\title{
LOAD TESTS OF PILED RAFT MODELS WITH DIFFERENT PILE HEAD CONNECTION CONDITIONS AND THEIR ANALYSES
}

\author{
Tatsunori Matsumoto ${ }^{\mathrm{i}}$, Hisashi Nemoto ${ }^{\mathrm{ii})}$, Hiroshi Mikami ${ }^{\mathrm{iii}}$,

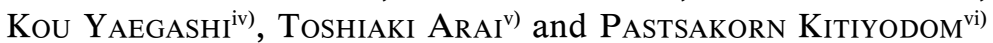

\begin{abstract}
A series of experimental and analytical studies on the behaviours of model pile groups and model piled rafts in dry sand subjected to static vertical loading and static cyclic horizontal loading were carried out in order to investigate the influence of various pile head connection conditions between the raft and the piles on the behaviours of the foundations models and to examine the applicability of an simplified analytical method to simulate the load tests. In the load tests, the behaviours of the model foundations were investigated in detail, with particular focus on cyclic horizontal loading, and behaviour such as horizontal stiffness and the rotation of the foundation, the load proportions between the raft and the piles, and the bending moments and shear forces generated in the piles. A simplified three-dimensional deformation analysis method was used to simulate the experiments.
\end{abstract}

Key words: 1-g test, analysis method, dry sand, horizontal load test, load proportion, pile group, pile head connection condition, piled raft, vertical load test (IGC: E13/E14/K7)

\section{INTRODUCTION}

Recently, piled raft foundation has been considered as a possible foundation type in Japan, especially in the design of building foundations. In making designs, estimations of deformation of the piled rafts during earthquakes is required. The authors are aware that a dynamic analysis of the foundation is essential in seismic design. This design approach is, however, complicated and may be still difficult in practice. A design method in which equivalent static horizontal loads are applied to the foundation structure is still one of the most practical design techniques used in Japan. Even when using this technique, the response of piled rafts subjected to static horizontal loading does become fully clarified, because the response of the piled raft is controlled by the load sharing of the vertical load between the raft and the piles, the interactions between the raft, the piles and the soil, as well as the connection condition between the pile head and the raft.

Correlation between the behaviours of model piled rafts during shaking and static horizontal loading were investigated using the centrifuge model provided by Horikoshi et al. (2003a, b) and the shaking table tests at 1-g field presented by Matsumoto et al. (2004a, b). In their experimental studies, two extreme pile head connection conditions, rigid connection and hinged connection conditions, were modelled. These experiments showed that the pile head connection condition is one of the key factors affecting the behaviours of piled rafts during shaking and static horizontal loading.

Hence, a series of experimental and analytical study on the behaviours of model piled rafts and model pile groups in dry sand subjected to static vertical loading and static cyclic horizontal loading were carried out in this research in order to investigate the influence of various pile head connection conditions on their behaviours. In the load tests, the behaviours of the model foundations during horizontal loading in particular such as horizontal stiffness and rotation of the foundation, load proportions between the raft and the piles, and bending moments and shear forces generated in the piles were investigated in detail.

Analyses of the load tests were also conducted using a simplified three-dimensional deformation analysis method in order to discuss the test results in more detail and to explore the possibility of the use of the simplified method for design purposes.

i) Graduate School of Natural Science and Technology, Department of Civil Engineering, Kanazawa University, Kanazawa, Japan (matsumot (at.kanazawa-u.ac.jp).

ii) Research Center, ANDO Corporation, Tokyo, Japan.

iii) Technological Development Center, Sumitomo Mitsui Construction Co. Ltd., Nagareyama, Japan.

iv) Building Engineering Department Technical Division, Hazama Corporation, Tokyo, Japan.

v) Technical Research Institute, Nishimatsu Construction Co. Ltd., Tokyo, Japan.

vi) Geotechnical \& Foundation Engineering Co., Ltd., Thailand.

The manuscript for this paper was received for review on January 28, 2009; approved on December 2, 2009.

Written discussions on this paper should be submitted before September 1, 2010 to the Japanese Geotechnical Society, 4-38-2, Sengoku, Bunkyo-ku, Tokyo 112-0011, Japan. Upon request the closing date may be extended one month. 


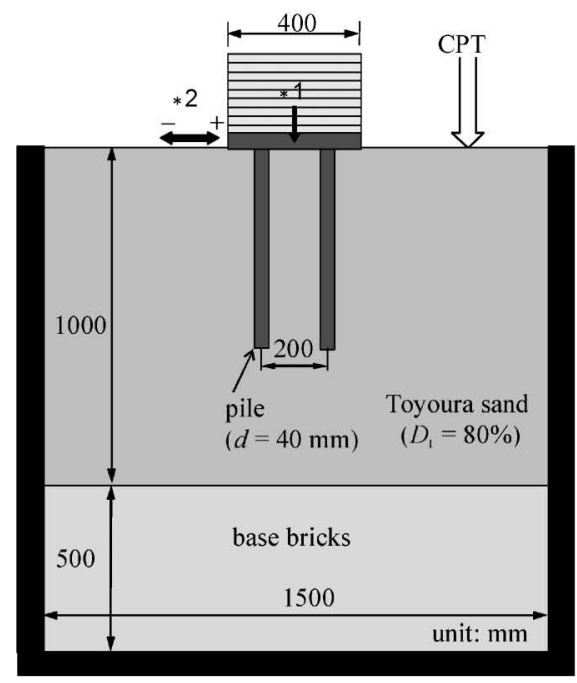

*1 Vertical loading by steel plates

*2 Cyclic horizontal loading by hydraulic jacks

(a) Whole set-up
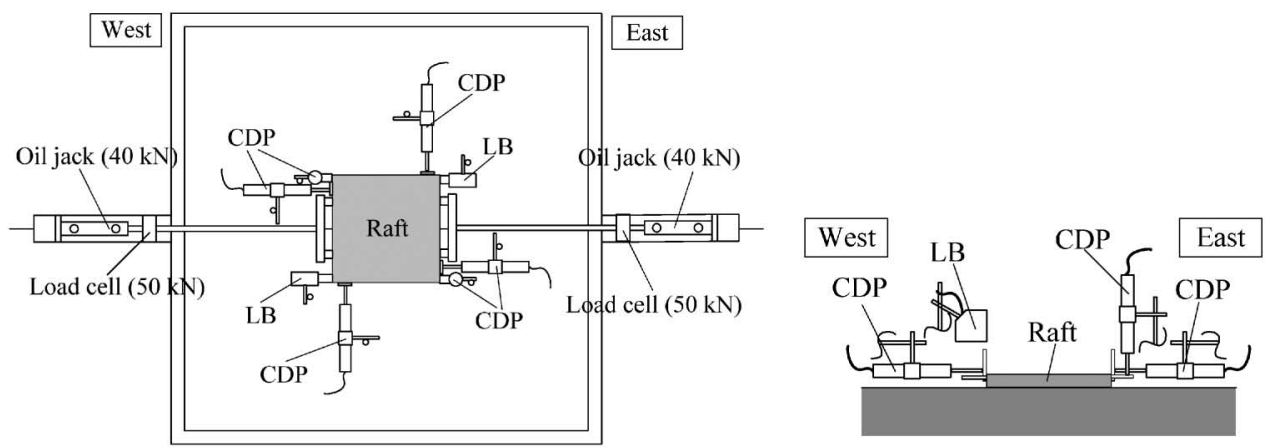

(b) Horizontal loading and measuring devices

Fig. 1. Illustration of test set-up

Table 1. Physical properties of Toyoura sand used for model tests

\begin{tabular}{l|l}
\hline \multicolumn{1}{c|}{ Property } & \multicolumn{1}{|c}{ Value } \\
\hline Maximum dry density, $\rho_{\mathrm{dmax}}$ & $1.621 \mathrm{t} / \mathrm{m}^{3}$ \\
Minimum dry density, $\rho_{\mathrm{dmin}}$ & $1.328 \mathrm{t} / \mathrm{m}^{3}$ \\
Density of soil particle, $\rho_{\mathrm{s}}$ & $2.637 \mathrm{t} / \mathrm{m}^{3}$ \\
Mean grain size, $D_{50}$ & $0.17 \mathrm{~mm}$ \\
Internal friction angle, $\phi^{\prime}$ & 40 degrees \\
\hline
\end{tabular}

\section{TEST DESCRIPTION}

\section{Model Ground and Model Foundations}

Figure 1 shows the test set-up including a model piled raft and the model ground. Dry Toyoura sand was used for the model ground throughout the tests. The physical properties of the Toyoura sand are summarised in Table 1 . The sand was prepared in a steel cubic box of $1500 \mathrm{~mm}$ in length. Note that base bricks were set at the bottom of the soil box to a level of $500 \mathrm{~mm}$ from the bottom. Thus, the effective height of the model ground was $1000 \mathrm{~mm}$.

Figures 2 and 3 show the model raft and the model piles, respectively. The square model raft was made of stainless steel plate with a width of $400 \mathrm{~mm}$ and a thickness of $40 \mathrm{~mm}$, and could be regarded as a 'rigid' plate.

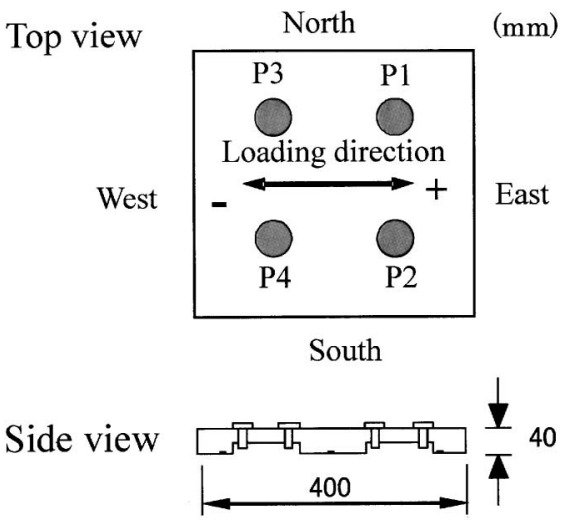

Fig. 2. Model raft

The Toyoura sand was glued at the bottom base of the model raft to increase the coefficient of friction between the raft base and the model ground.

Aluminum pipe piles with an outer diameter of $40 \mathrm{~mm}$, a wall thickness of $2 \mathrm{~mm}$ and a length of $600 \mathrm{~mm}$ were used for the model piles. The top and bottom of the pipe pile were capped with an aluminum plate. The geometrical and mechanical properties of the model pile are listed 

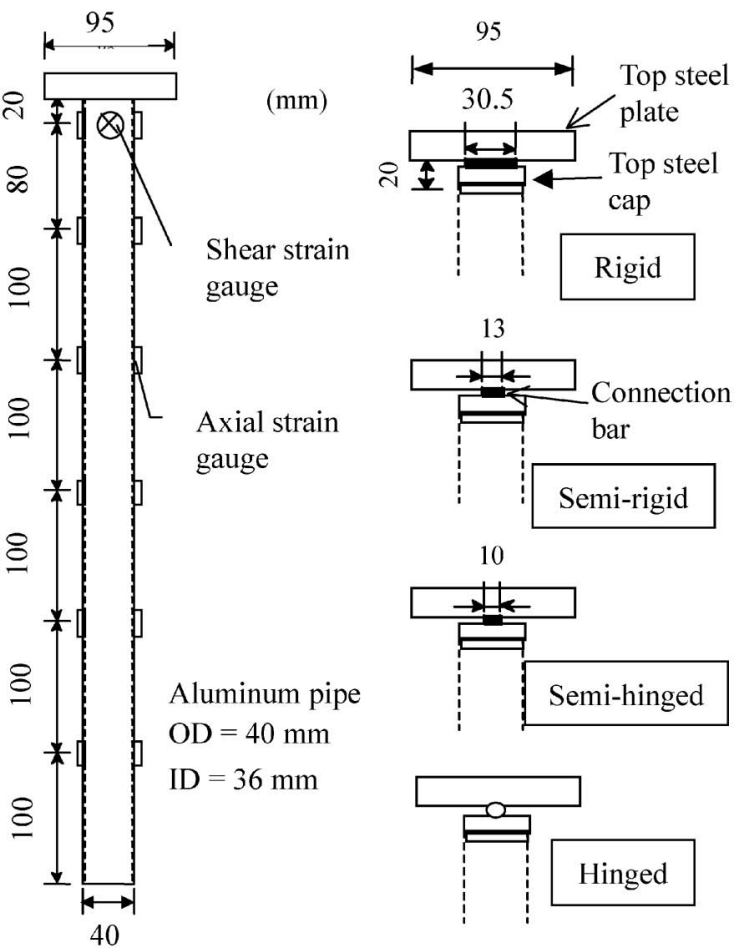

Fig. 3. Model piles with different pile head connection conditions

Table 2. Geometrical and mechanical properties of the model pile

\begin{tabular}{l|c}
\hline \multicolumn{1}{c|}{ Property } & \multicolumn{1}{c}{ Value } \\
\hline Outer diameter, $d$ & $40 \mathrm{~mm}$ \\
Wall thickness, $t_{\mathrm{w}}$ & $2 \mathrm{~mm}$ \\
Length, $L$ & $600 \mathrm{~mm}$ \\
Cross sectional area, $A_{\mathrm{p}}$ & $239 \mathrm{~mm}^{2}$ \\
Young's modulus, $E_{\mathrm{p}}$ & $7.0 \times 10^{7} \mathrm{kPa}$ \\
Poisson's ratio, $v_{\mathrm{p}}$ & 0.3 \\
Longitudinal rigidity, $E_{\mathrm{p}} A_{\mathrm{p}}$ & $1.67 \times 10^{4} \mathrm{kN}$ \\
Bending rigidity, $E_{\mathrm{p}} I_{\mathrm{p}}$ & $3.03 \mathrm{kNm}^{2}$ \\
\hline
\end{tabular}

in Table 2. The Toyoura sand was glued on the outer shaft of the model piles to increase the shaft resistance.

Four different pile head connection conditions were modelled by using connection bars with a length of $5 \mathrm{~mm}$ between the top steel cap and the raft. The connection bars had different diameters, $30.5 \mathrm{~mm}, 13.0 \mathrm{~mm}$ and 10.0 $\mathrm{mm}$, as shown in Fig. 3. The bending rigidities, $E_{\mathrm{b}} I_{\mathrm{b}}$, of these connection bars are $2.974,0.098$ and $0.034 \mathrm{kN} \cdot \mathrm{m}^{2}$, respectively. A ball joint (Photo 1) was used to simulate the hinged pile head connection condition. These pile head connection conditions are called 'rigid', 'semirigid', 'semi-hinged' and 'hinged', respectively. Note here that $E_{\mathrm{b}} I_{\mathrm{b}}$ of the connection bars of the rigid, semirigid and semi-hinged models are about $1,1 / 30$ and $1 / 90$ of the bending rigidity of the model pile, $E_{\mathrm{p}} I_{\mathrm{p}}$, of 3.03 $\mathrm{kNm}^{2}$.

The top steel plate, the connection bar and the top steel cap was made as a unit for each of the rigid, semi-rigid and semi-hinged models. The top steel cap was stiffly pushed into the top of the model pile and welded to the model pile.

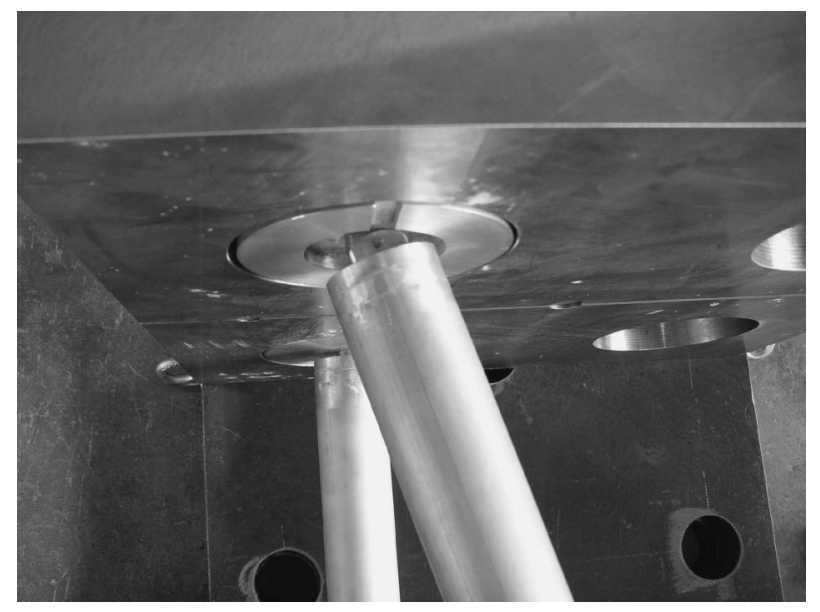

Photo 1. Ball joint used in the hinged connection condition

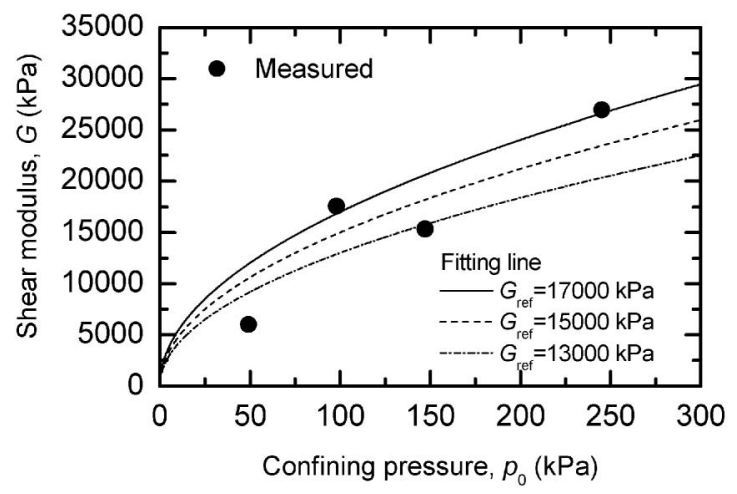

Fig. 4. Shear modulus vs confining pressure of the Toyoura sand, together with the fitting lines

\section{Mechanical Properties of Toyoura Sand}

A series of triaxial consolidated drained shear tests (CD test) of the Toyoura sand were conducted to obtain the stress dependency of the shear modulus, $G$, and the internal friction angle, $\phi^{\prime}$. The tests were carried out with soil specimens of relative density $D_{\mathrm{r}}=80 \%, 100 \mathrm{~mm}$ in height and $50 \mathrm{~mm}$ in diameter, with different confining pressures, $p_{0}$, of 49, 98, 147 and $245 \mathrm{kPa}$. From initial linear part of the measured deviator stress, $q$, versus shear strain, $\gamma=\varepsilon_{\mathrm{a}}-\varepsilon_{\mathrm{r}}\left(\varepsilon_{\mathrm{a}}\right.$ and $\varepsilon_{\mathrm{r}}$ are axial and radial strains, respectively), for each test, the shear modulus was estimated as $G=q / \gamma$, and was plotted against the confining pressure, $p_{0}$, in Fig. 4 . The measured values of $G$ are fitted by the lines in Fig. 4, which are expressed as

$$
G=G_{\text {ref }}\left(p_{0} / p_{\text {ref }}\right)^{0.5}
$$

where $p_{\text {ref }}$ is a reference value of confining pressure $(=100$ $\mathrm{kPa})$ and $G_{\text {ref }}$ is the value of $G$ at $p_{0}=p_{\text {ref }}$.

It may be seen from Fig. 4 that the shear modulus of the sand is proportional to the square root of $p_{0}$.

Figure 5 shows the peak deviator stress versus the effective mean stress from the CD tests. From this relation, the internal friction angle, $\phi^{\prime}$, was estimated at 40 degrees. 


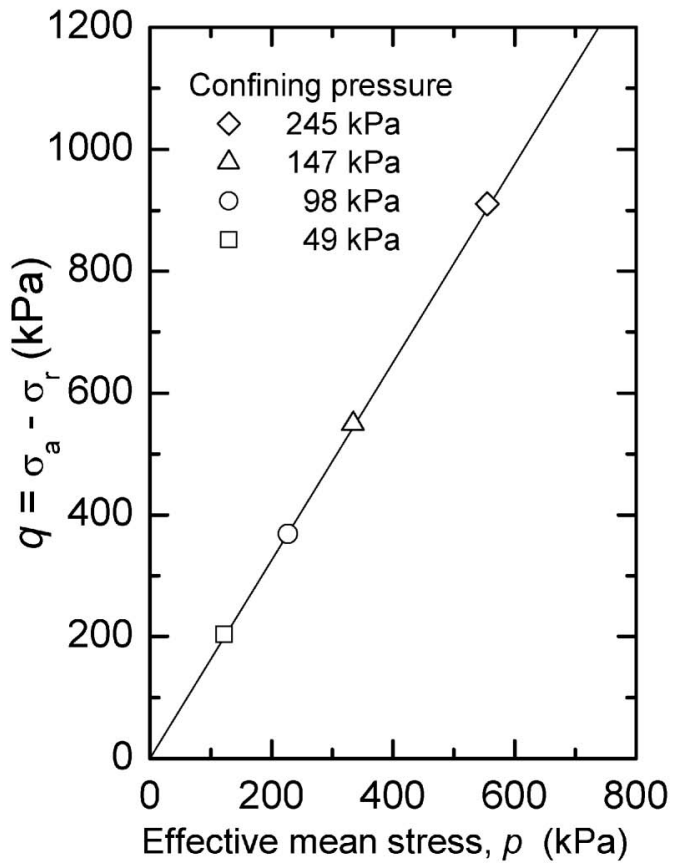

Fig. 5. Peak deviator stress versus effective mean stress

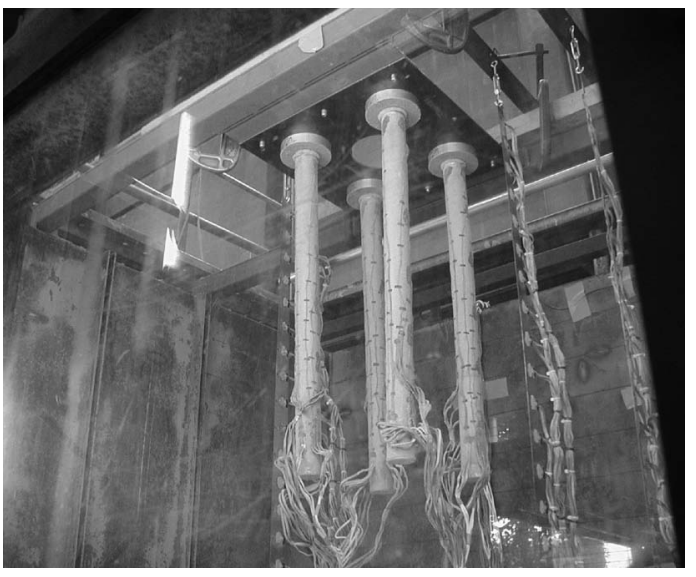

Photo 2. Model foundation with instruments

\section{Test Procedure and Test Cases}

The method of setting-up of the model foundation in the model ground was as follows. First, four model piles were set in the soil box at the prescribed positions with centre-to-centre distance of $200 \mathrm{~mm}$ by using specially designed rigs ( see Photo 2). Second, the sand was poured into the soil box to have a thickness of $100 \mathrm{~mm}$, and was compacted using a vibrator until it had a relative density, $D_{\mathrm{r}}$, of about $80 \%$. This procedure was repeated until the model ground was $1000 \mathrm{~mm}$ thick. Third, the model raft was placed on the model piles, and the top steel plate on each pile head was bolted to the raft.

A total of 7 test cases were carried out as listed in Table 3. Case 1 is the test on the raft alone, Cases 2 and 3 are the tests on the pile groups with rigid and hinged pile head connection conditions, and Cases 4 to 7 are the tests on the piled rafts with the four different pile head connection
Table 3. Test cases and pile head connection conditions

\begin{tabular}{l|l|c}
\hline \multicolumn{1}{c|}{ Test name } & $\begin{array}{c}\text { Type of } \\
\text { foundation }\end{array}$ & $\begin{array}{c}\text { Pile head } \\
\text { connection condition }\end{array}$ \\
\hline Case 1: Raft & Raft alone & - \\
Case 2: PG-R & Pile Group & Rigid \\
Case 3: PG-H & Pile Group & Hinged \\
Case 4: PR-R & Piled Raft & Rigid \\
Case 5: PR-SR & Piled Raft & Semi-rigid \\
Case 6: PR-SH & Piled Raft & Semi-hinged \\
Case 7: PR-H & Piled Raft & Hinged \\
\hline
\end{tabular}

PG: Pile Group, PR: Piled Raft

R: Rigid connection, SR: Semi-rigid connection

$\mathrm{H}$ : Hinged connection, SH: Semi-hinged connection

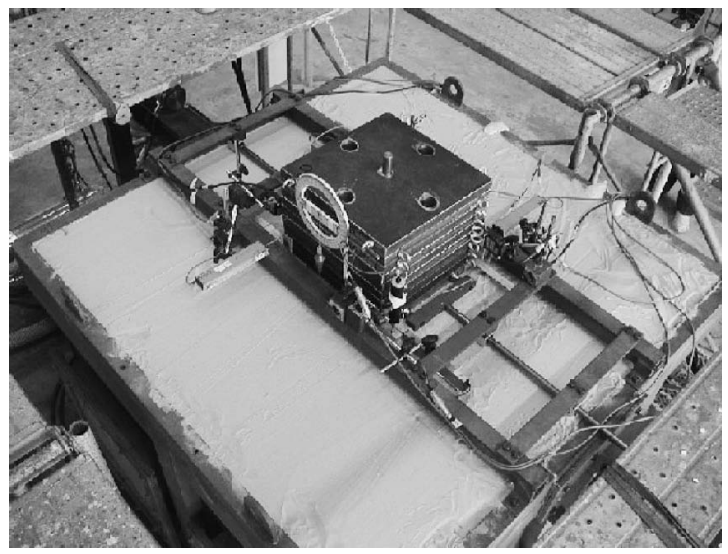

Photo 3. Test set-up prior to cyclic horizontal load tests

conditions. Note that, in the cases of the pile groups, a gap of $5 \mathrm{~mm}$ between the raft base and the ground surface was made prior to the start of the load test, while in the cases of the piled rafts, the raft base was attached to the ground surface at the start of the test.

The loading process on the model foundation was divided into two stages, i.e., vertical loading stage and cyclic horizontal loading stage. In the vertical loading stage, the vertical load was applied by placing 9 steel plates with a weight of $0.376 \mathrm{kN}$ each on the model raft one by one. Finally, a maximum vertical load of $3.384 \mathrm{kN}$ was applied to the model foundation. Note that the average contact stress of the raft was $21.2 \mathrm{kPa}$ for the case of raft alone. After the completion of vertical loading stage, cyclic horizontal loads were applied to the model raft by means of two oil jacks in the east and west directions. The horizontal load and horizontal displacement to the east direction are taken as positive in this paper.

During the load test, the horizontal load, the vertical and horizontal displacements of the raft, the axial forces and shear forces, and the bending moments of each pile were measured. Photo 3 shows the test set-up prior to cyclic horizontal load test.

The horizontal cyclic loading and measuring devices are shown in Fig. 1(b). Two oil jacks were placed on the east and west sides of the soil box. A steel loading bar was connected to each oil jack. The end of the steel loading bar was attached with a roller that was in contact with the 
model raft at the mid-height of the raft $(20 \mathrm{~mm}$ above the ground surface). When the horizontal displacement in the west direction was applied, the pushing force was applied to the raft using the oil jack on the east side while the oil jack on the west side was released. When the horizontal displacement in the east direction was applied, a pushing force was applied to the raft using an oil jack on the west side while the oil jack on the east side was released. The horizontal loads applied to the raft were measured by means of two load cells attached between the raft and the steel loading bars.

Horizontal displacement and vertical displacements of the raft were measured by means of laser beam displacement meters (LB in Fig. 1(b)) with a precision of $8 \mu \mathrm{m}$ and contact displacement meters (CDP in Fig. 1(b)). From the measured vertical displacements, the average vertical displacement and the inclination of the raft were obtained.

Axial forces and bending moments of the model piles were estimated from the measured axial strains, and shear forces were estimated from the shear strain gauges (cross-gauges) near the pile top, based on the elastic beam theory.

\section{TEST RESULTS}

\section{Results of Cone Penetration Tests}

In order to compare the test results of the 7 test cases listed in Table 3, compatibility of the soil conditions between the test cases was confirmed by conducting a cone penetration test (CPT) in the model ground after the completion of the load test in each case. A miniature cone penetrometer with a diameter of $16.2 \mathrm{~mm}$ and an apex angle of 60 degrees was penetrated in the model ground at a penetration rate of $2 \mathrm{~mm} / \mathrm{s}$. The location of the CPT was $300 \mathrm{~mm}$ away from the edge of the raft in order to minimise the influence of soil disturbance due to the loading process of the foundation.

The distributions of the cone tip resistance, $q_{\mathrm{c}}$, with depth for the model grounds in all the test cases are shown in Fig. 6. Although some scatters are seen in $q_{\mathrm{c}}$ for depths greater than $300 \mathrm{~mm}$ between the test cases, it may be said that compatibility of the model ground conditions between all the test cases was achieved.

\section{Results of Vertical Load Tests}

Figure 7 shows the relationships of the vertical load, $P$, and the settlement, $w$, of the model foundations. Although the measured settlements were very small compared to the width of the raft $(400 \mathrm{~mm})$, it can be clearly seen from the figure that the settlements of the pile groups (Cases 2 and 3 ) were much smaller compared with the raft alone. It is also seen that the settlements of the piled rafts (Cases 4 to 7) were smaller than those of the pile groups, indicating the effect of the raft. It should be noted that pile head connection condition had little influence on the settlements in both types of the foundations.

Figure 8 shows the changes in the vertical load proportion carried by the raft with an increase in the vertical

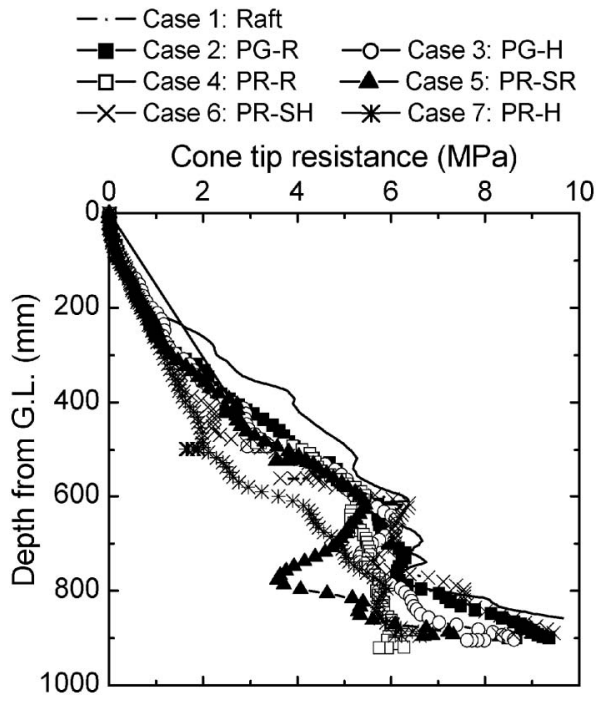

Fig. 6. Results of CPTs in the model grounds

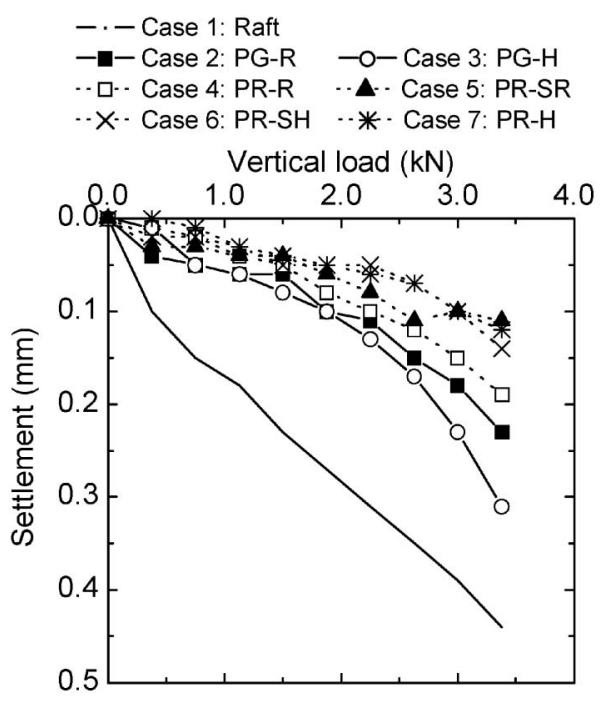

Fig. 7. Vertical load - settlement relationship

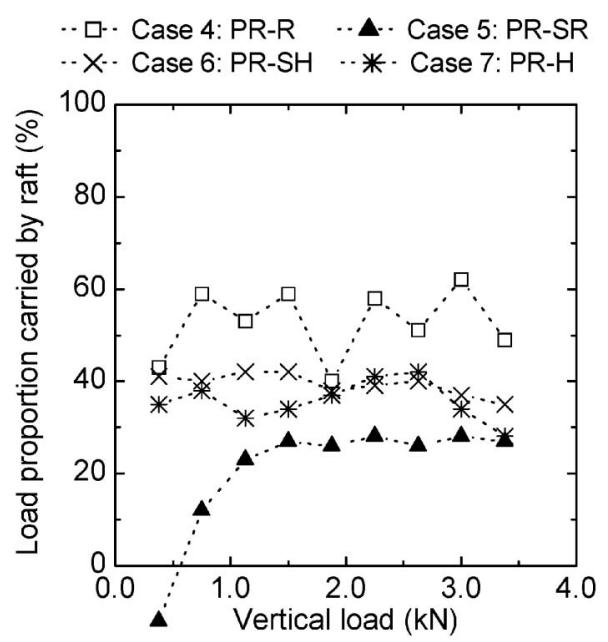

Fig. 8. Vertical load - vertical load proportion relationship 
load. The load carried by the raft was calculated by subtracting the axial forces at the pile head of 4 piles from the weight applied on the raft. Of course, the proportion of the vertical load carried by the piles is $100 \%$ in the case of the pile groups. In PR-SR (Case 5), the load proportion carried by the raft had a negative value when a vertical load of $0.38 \mathrm{kN}$ was applied, which is unrealistic, and a smaller value when a vertical load of $0.76 \mathrm{kN}$ was applied. It seems that these values are erroneous due to the small values of the vertical load. Except for these data, it is seen from Fig. 8 that the vertical load proportion is almost constant irrespective of the amplitude of the vertical load in all the pile raft cases. The load proportion carried by the raft is the highest in PR-R (Case 4), and that is the lowest in PR-SR (Case 5). The load proportions carried by the raft in PR-SH (Case 6) and PR-H (Case 7) are similar and intermediate between PR-R and PR-SR. Hence, it may be said that the pile head connection condition has little influence on the vertical load proportion. This aspect will be discussed later again in the Section of
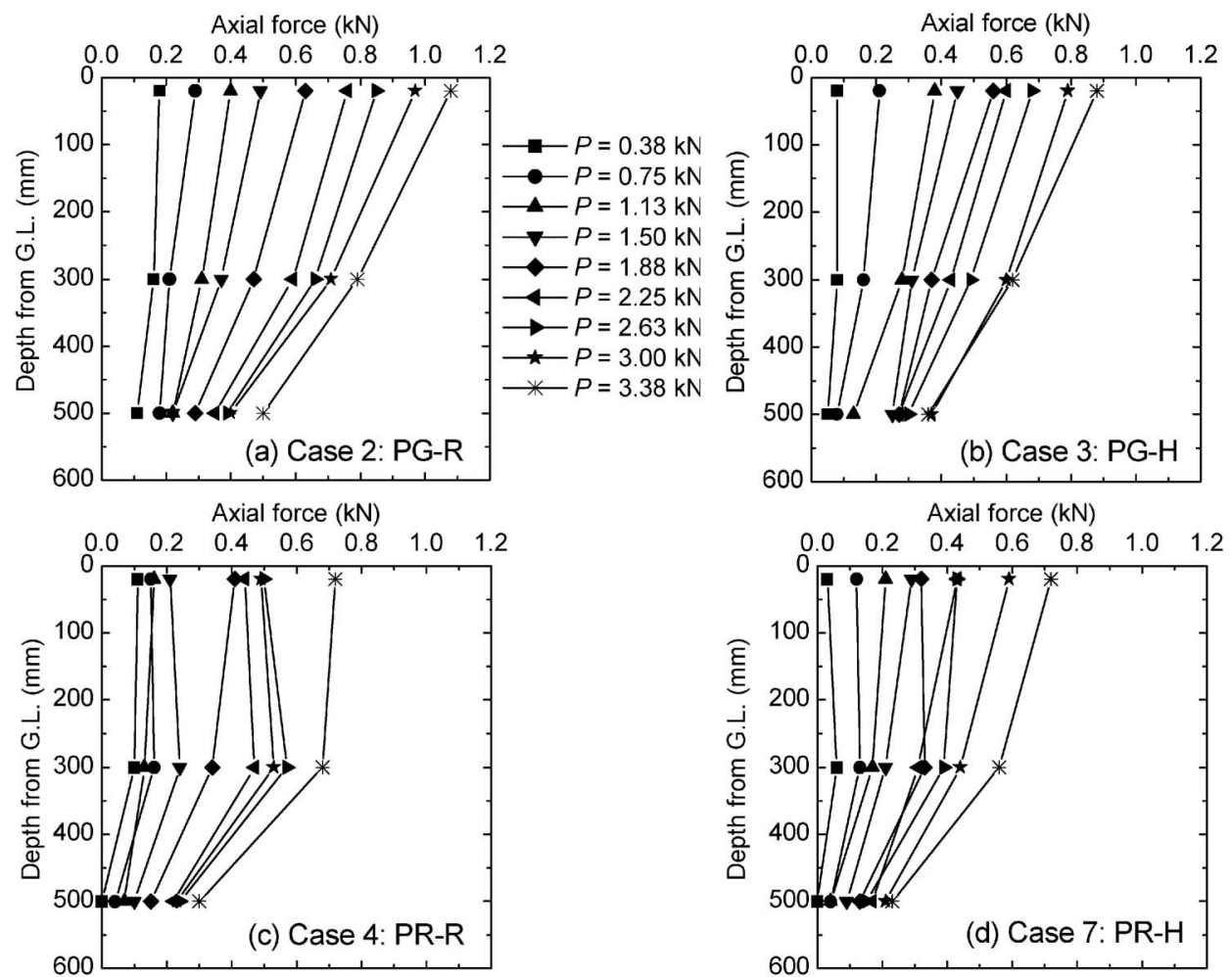

Fig. 9. Change in axial force distribution in pile

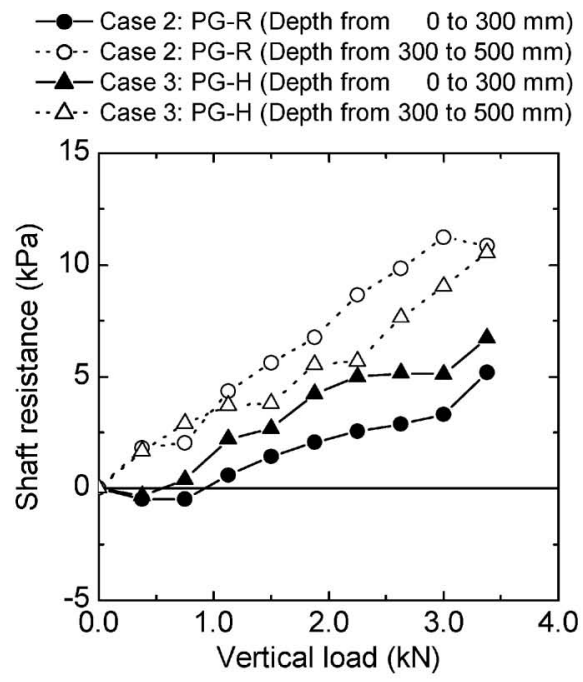

(a) Case 2: PG-R and Case 3: PG-H

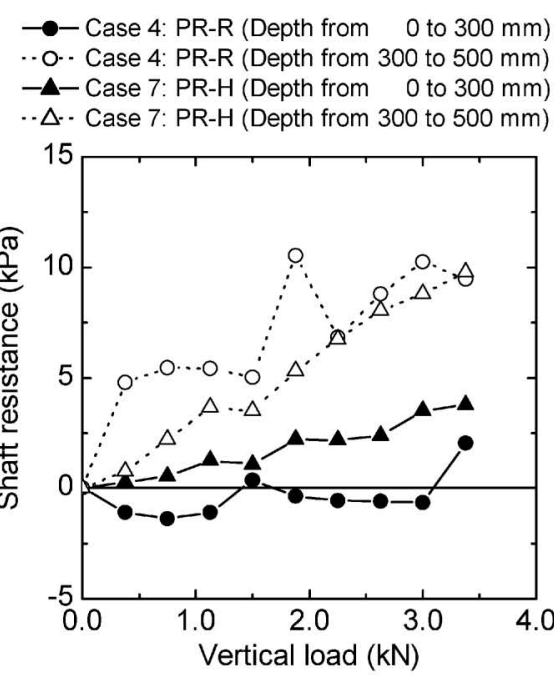

(b) Case 4: PR-R and Case 7: PR-H

Fig. 10. Vertical load - pile shaft resistance relationship 
"ANALYSES OF LOADING TESTS".

It is interesting to note that the vertical load proportion carried by the raft typically ranges from 30 to $60 \%$ in the field measurements of building foundations (Kakurai, 2003). The results of Fig. 8 correspond to the field measurements by Kakurii (2003).

Figure 9 shows the measured changes in axial force distribution in a pile within the pile groups or piled rafts with increase in the vertical load for the cases of PG-R, PG-H, PR-R and PR-H. Note here that axial strains were measured at three levels of the model piles due to the limitation of data recording device, although the strain
Table 4. Vertical load proportion carried by the raft prior to horizontal loading

\begin{tabular}{l|c|c}
\hline \multicolumn{1}{c|}{ Test name } & Type of foundation & $\begin{array}{c}\text { Vertical load proportion } \\
\text { carried by the raft (\%) }\end{array}$ \\
\hline Case 1: Raft & Raft alone & 100 \\
Case 2: PG-R & Pile Group & 0 \\
Case 3: PG-H & Pile Group & 0 \\
Case 4: PR-R & Piled Raft & 49 \\
Case 5: PR-SR & Piled Raft & 27 \\
Case 6: PR-SH & Piled Raft & 35 \\
Case 7: PR-H & Piled Raft & 28 \\
\hline
\end{tabular}

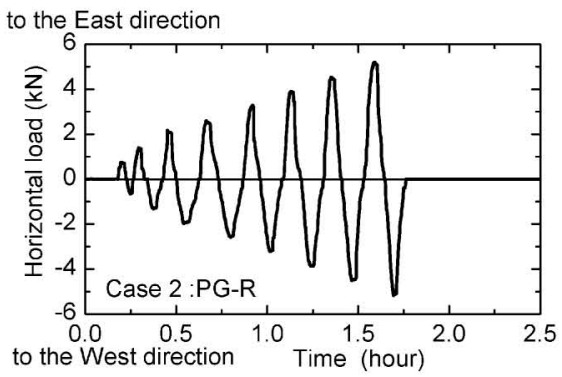

(b) Case 2: PG-R

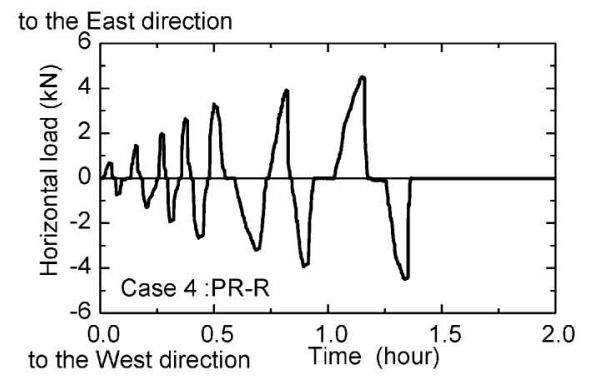

(d) Case 4: PR-R

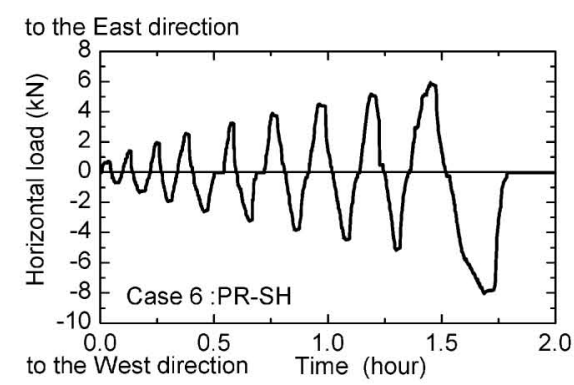

(f) Case 6: PR-SH

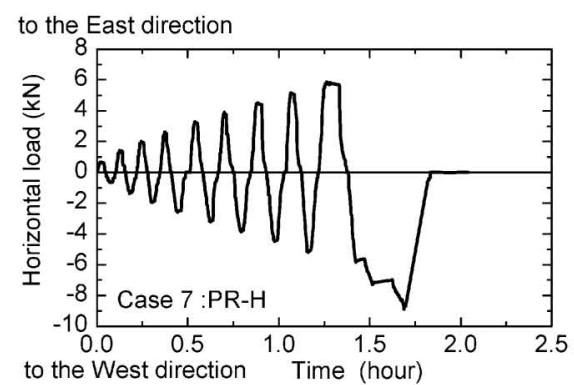

(g) Case 7: PR-H

Fig. 11. Horizontal loading cycles 
gauges were attached at five levels of the pile model piles. As might be expected, large axial pile forces were generated in the piles in the pile groups compared with those in the piled rafts. It is interesting to note that there is a distinct difference between the axial force distributions of the pile group and the piled raft. The axial force decreases almost linearly from the pile head to the pile base in the case of the pile group (Figs. 9(a) and (b)), whereas the axial forces from the pile head to a depth of $300 \mathrm{~mm}$ is relatively constant for each vertical load in the case of the piled rafts (Figs. 9(c) and (d)), indicating interactions between the piles and the raft.

The changes in shaft resistance with increase in the vertical load are shown in Fig. 10 for the pile groups and the piled rafts, respectively. It can be said that the influence of the pile head connection condition is very small for the development of the shaft resistance in both the pile groups and the piled rafts, and that the shaft resistance along the lower part of the pile (depth from $300 \mathrm{~mm}$ to $500 \mathrm{~mm}$ ) is almost equal between the pile group and the piled rafts.

\section{Results of Cyclic Horizontal Load Tests}

The vertical load proportion carried by the raft when a vertical load of $3.384 \mathrm{kN}$ was applied to the raft prior to the start of horizontal loading is listed in Table 4. In the cases of the piled rafts (Cases 4 to 7), the vertical load proportion carried by the raft may be comparable be- tween the test cases, although the vertical load proportion was higher in Case 4.

Figure 11 shows the horizontal loading cycles employed in the all test cases. A horizontal load to the East direction is taken as positive. Similar horizontal loading cycles were applied to the model foundations in all test cases.

Figure 12 shows the relationship between the horizontal load, $H$, and the horizontal displacement, $u$, of the raft for all the test cases. In Case 1: Raft, the horizontal load attained its peak at a horizontal displacement of 5 $\mathrm{mm}$, and then gradually decreased with increasing horizontal displacement and reached the residual load at a horizontal displacement of $10 \mathrm{~mm}$. The pile head connection condition on the horizontal load versus the horizontal displacement was found to have an influence in both the pile groups and the piled rafts. In order to show this influence clearly, the horizontal load versus the horizontal displacement at the maximum positive load in each loading cycle is indicated in Fig. 13. It is interesting that the horizontal stiffness of the raft alone (Case 1) was larger than that of PG-H (Case 3) and almost equal to that of PG-R (Case 2) for small horizontal loads, although the horizontal resistance of PG-H and PG-R exceeded that of the raft alone for large horizontal displacements. The horizontal stiffness of the piled rafts were larger than those of the pile groups. The horizontal stiffness of PR-SH (Case 6) was slightly larger than that of
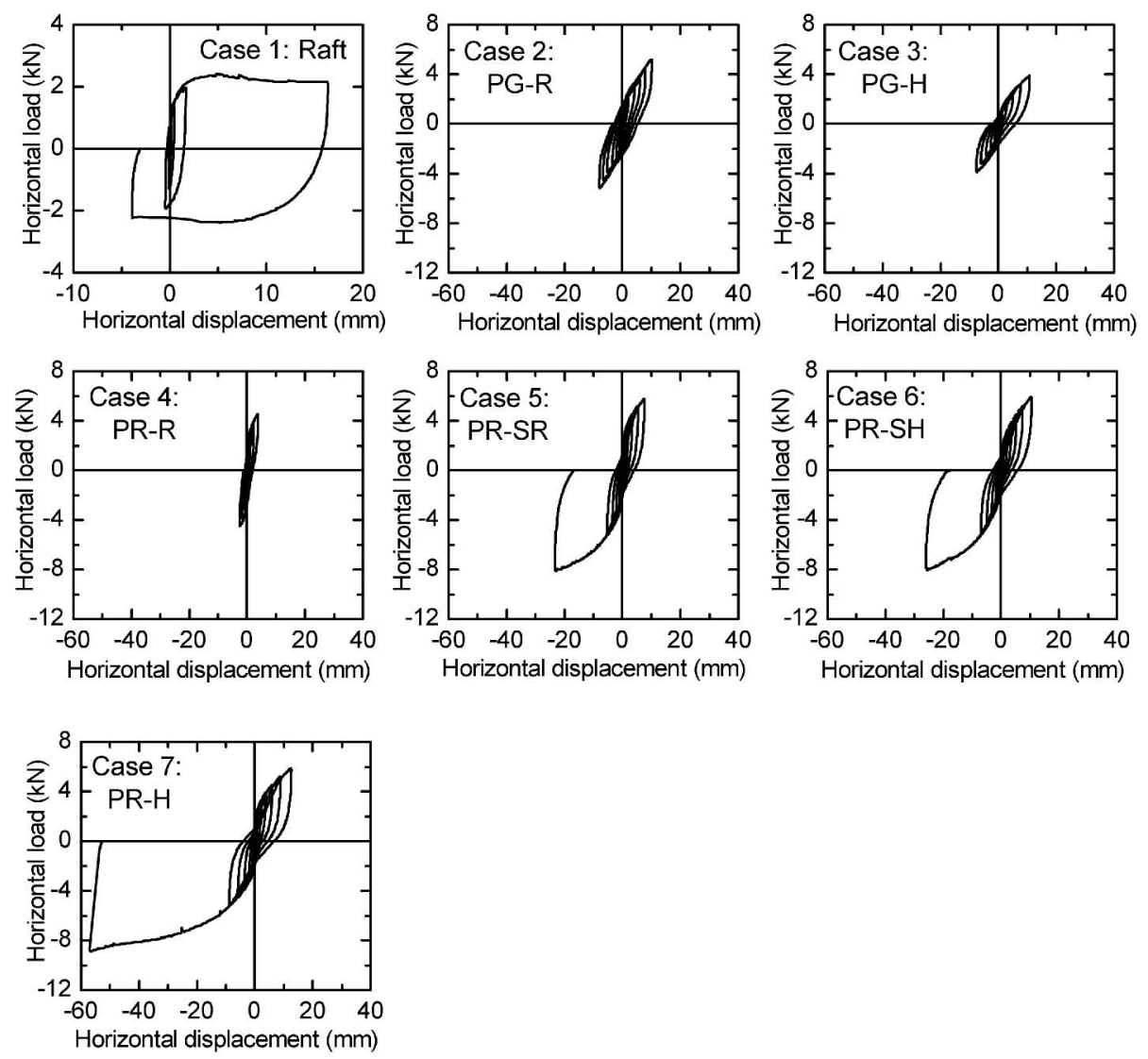

Fig. 12. Horizontal load versus horizontal displacement 


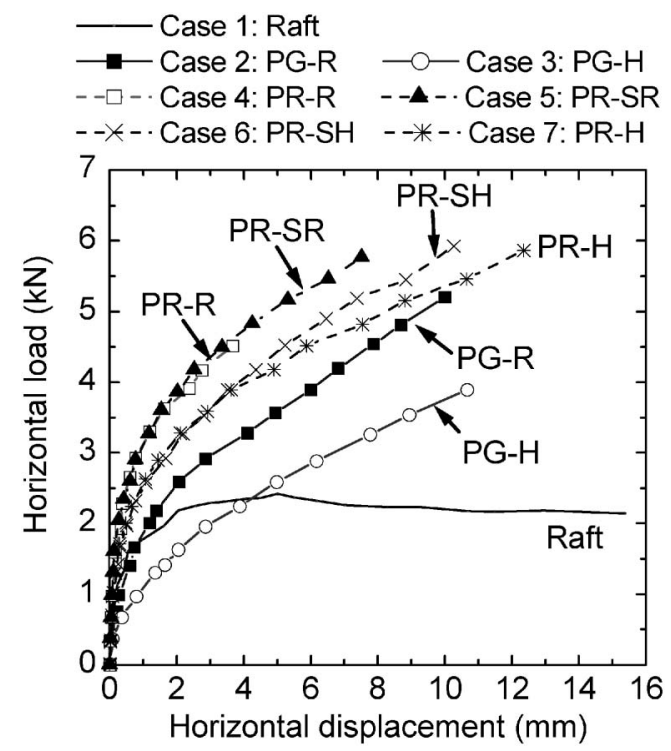

Fig. 13. Horizontal load vs horizontal displacement at maximum load in each cycle for all the test cases

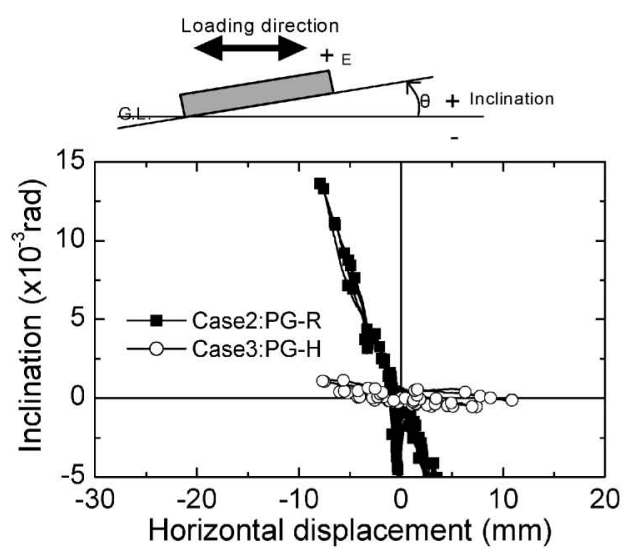

(a) Pile group
PR-H (Case 7). The horizontal stiffness of PR-SR (Case 5) and PR-R (Case 4) were almost identical, and were significantly larger than those of PR-SH and PR-H.

Figure 14 shows the relationships between the inclination of the raft and the horizontal displacement. A very large inclination is induced at a given horizontal displacement in the pile group with the rigid pile head connection (PG-R). The inclination is largely suppressed in the pile group with the hinged pile head connection (PG-H). As can be also seen in the cases of the pile raft, the inclination of the raft decreases as the pile head connection becomes less rigid (i.e., the inclination of $\mathrm{PR}-\mathrm{H}<\mathrm{PR}$ $\mathrm{SH}<\mathrm{PR}-\mathrm{SR}<\mathrm{PR}-\mathrm{R}$ ). If we compare PG-R and PR-R or $\mathrm{PG}-\mathrm{H}$ and $\mathrm{PR}-\mathrm{H}$, the inclination of the piled raft is smaller than that of the corresponding pile group, indicating that the raft acts effectively to suppress inclination. It can be said that lower pile head connection rigidity suppresses the rotation of the foundation compared with higher pile head connection rigidity for a given horizontal displacement, although lower pile head connection rigidity results in larger horizontal displacement for a given horizontal load.

Figure 15 shows the relationships between the inclination of the raft and the horizontal load in cases of (a) pile

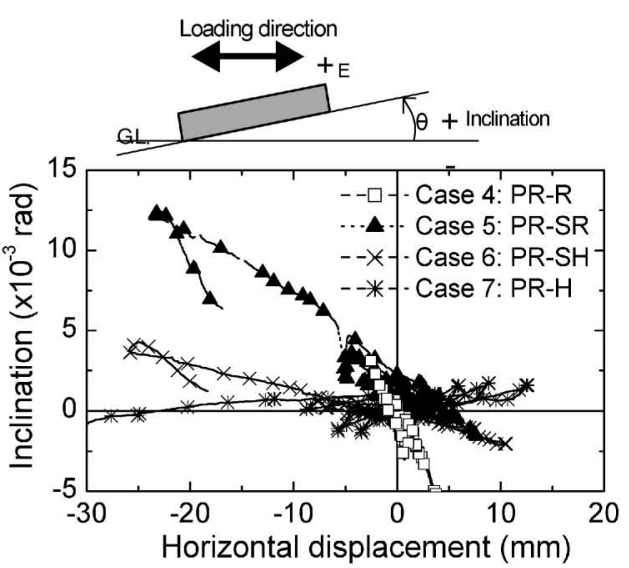

(b) Piled raft

Fig. 14. Inclination of raft versus horizontal displacement

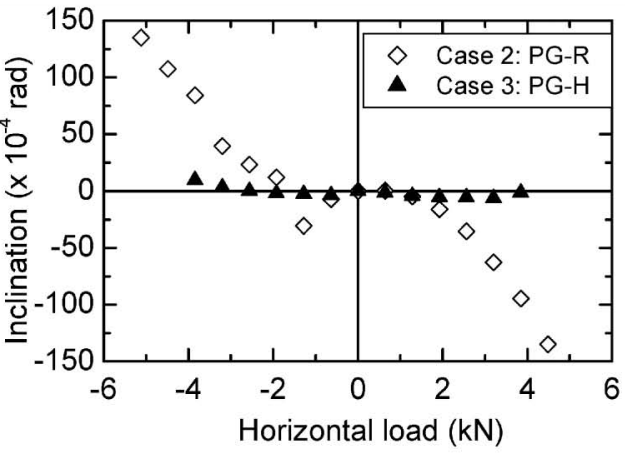

(a) Pile group

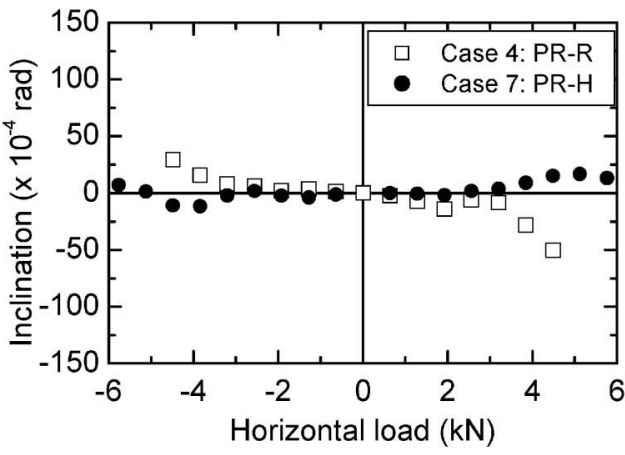

(b) Piled raft

Fig. 15. Peak horizontal load in each loading cycle versus inclination 


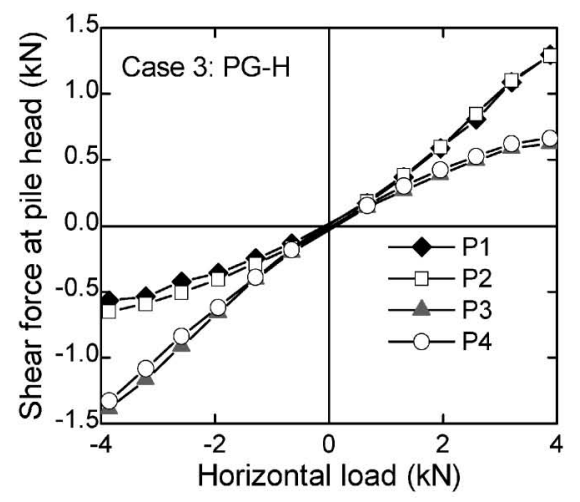

(a) Case 3: PG-H

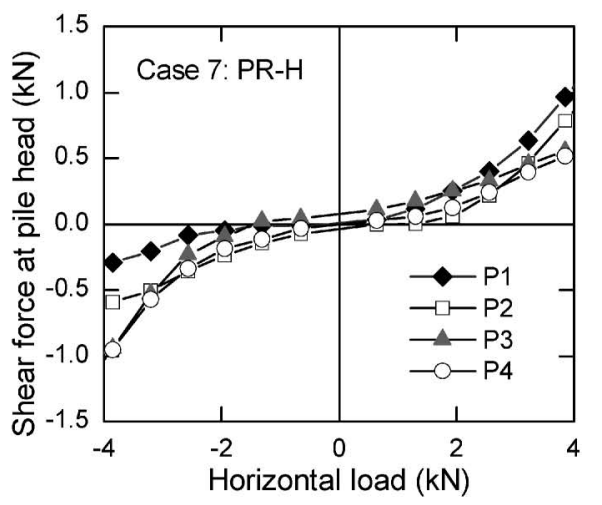

(b) Case 7: PR-H

Fig. 16. Shear force at pile head versus horizontal load

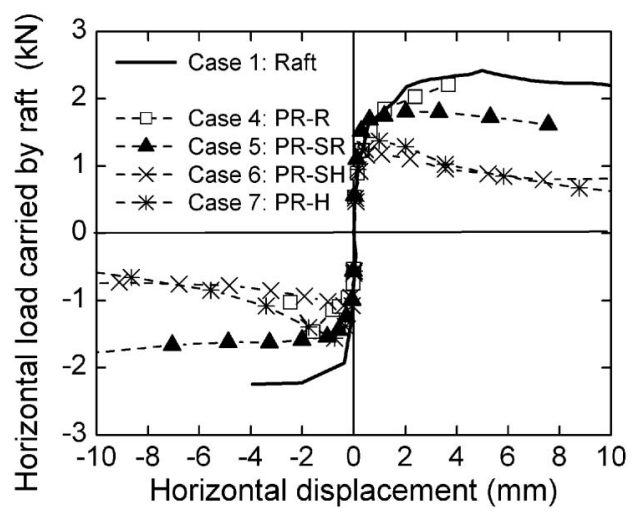

Fig. 17. Load carried by raft versus horizontal displacement

groups and (b) piled rafts with rigid and hinged pile head connection conditions. It is seen that little inclination of the raft occurred in either the pile group or the piled rafts with hinged pile head connection condition. If we compare the pile group and piled raft with rigid pile head connection condition (PG-R and PR-R), it is seen again that the existence of the raft resistance effectively suppressed the inclination of the raft.

Figure 16 shows examples of the relationships of the shear force at pile head and the horizontal load in Case 3 (PG-H) and Case 7 (PR-H). In both cases, the shear forces at the head of the front piles (P1 and $\mathrm{P} 2$ for positive horizontal load, or P3 and P4 for negative horizontal load) are larger than those of the rear piles. Similar behaviours were observed in the other test cases of the pile groups and the piled rafts. If we compare the shear forces in the piles at the same horizontal load between Case 3 (PG-H) and Case 7 (PR-H), the shear forces in the piles in the piled raft are smaller than those in the pile group, indicating that the raft base resistance makes a significant contribution.

Figure 17 shows the relationships between the horizontal load carried by the raft in the piled rafts and the horizontal displacement. Figure 18 shows the relationships between the horizontal load carried by the piles in the piled rafts and in the pile groups and the horizontal

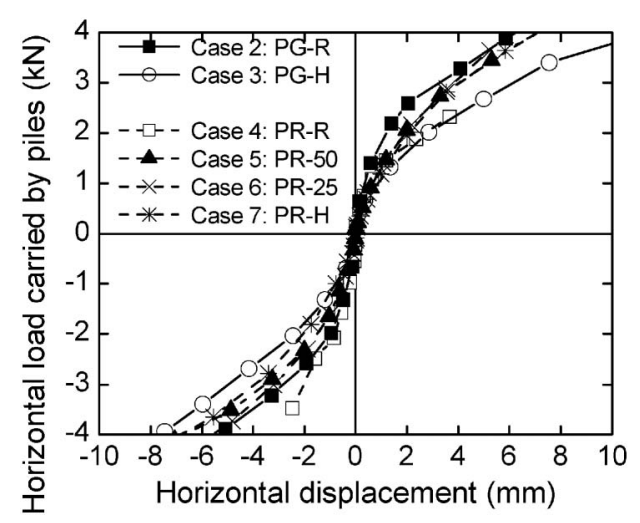

Fig. 18. Load carried by pile versus horizontal displacement

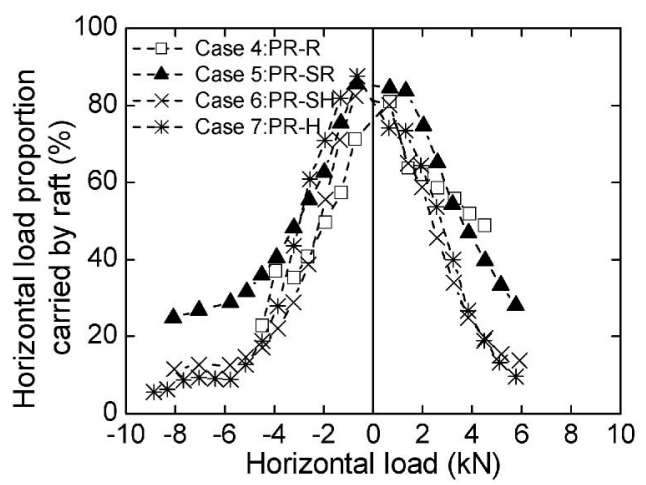

Fig. 19. Load proportion carried by raft versus horizontal load

displacement. It can be seen from Fig. 17 that the horizontal load carried by the raft at a given horizontal displacement becomes smaller as the pile head connection becomes less rigid. It can be seen from Fig. 18 that the horizontal loads carried by the piles in the piled rafts at a given horizontal displacement lie between PG-R and PG$H$. The higher load carried by the piles in the piled rafts than in PG-H is thought to be due to the increase in the strength and the rigidity of the soil beneath the raft caused by the load transfer from the raft base to the soil. It can also be seen from Fig. 18 that the pile head connec- 


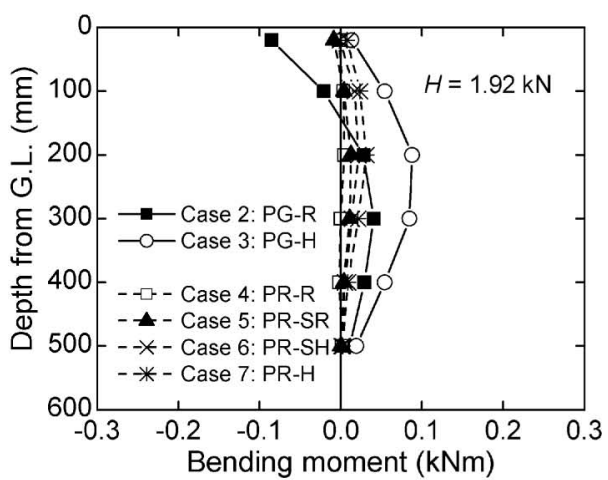

(a) at $H=1.92 \mathrm{kN}$

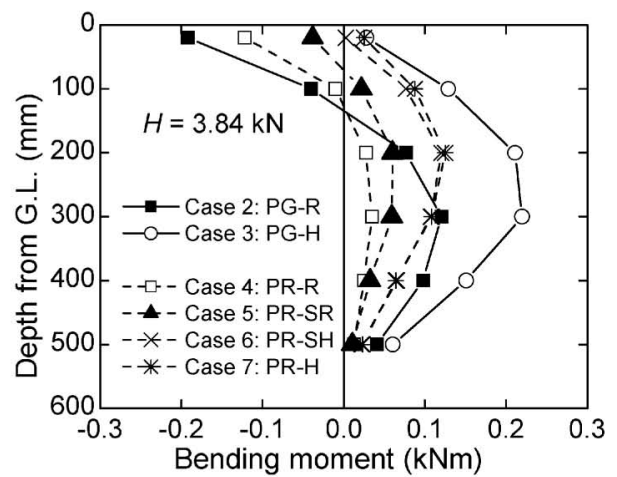

(b) at $H=3.84 \mathrm{kN}$

Fig. 20. Distributions of bending moments in P1

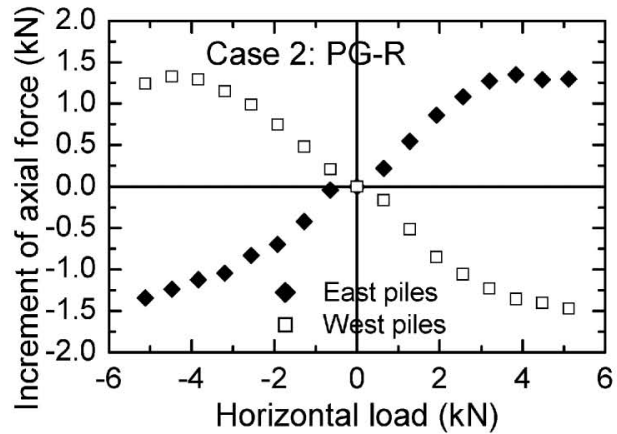

(a) Case 2: PG-R

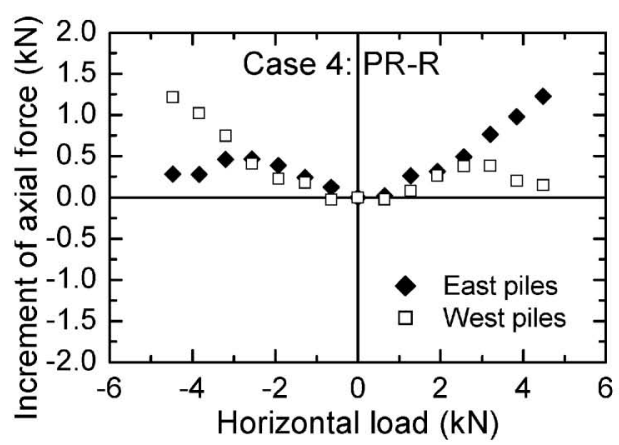

(c) Case 4: PR-R

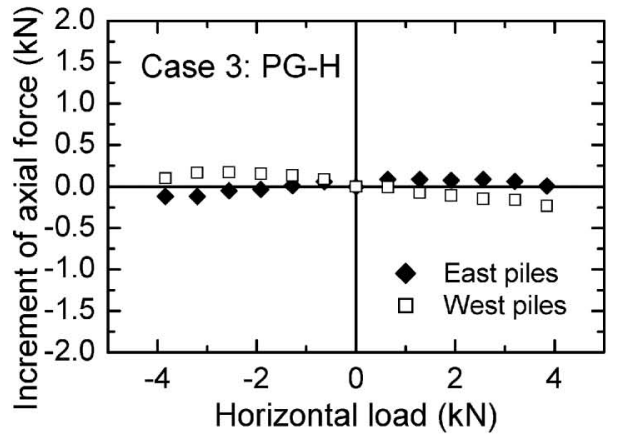

(b) Case 3: PG-H

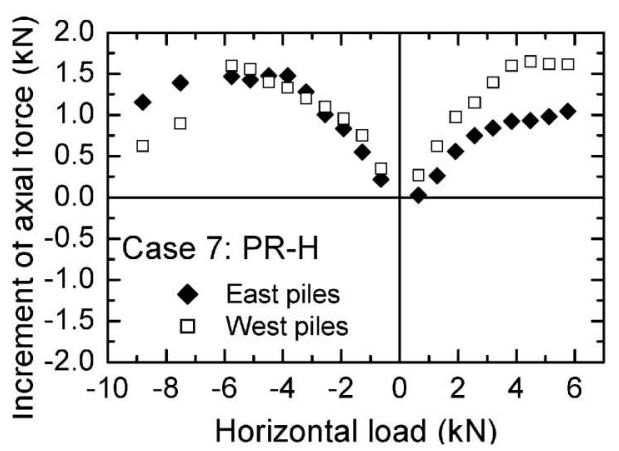

(d) Case 7: PR-H

Fig. 21. Peak horizontal load in each loading cycle versus axial load on piles

tion rigidity has little influence on the horizontal load carried by the piles in the piled rafts.

Figure 19 shows the relationships between the horizontal load proportion carried by the raft and the horizontal load. The horizontal load proportion carried by the raft is about $80 \%$ for initial loading stages and decreases with increasing horizontal load. This suggests that the raft acts as a 'horizontal displacement reducer' for initial loading stages, and that the horizontal resistance of the piles is effectively mobilised after the slippage of the raft base occurs. For large horizontal loads, the horizontal load proportion carried by the raft is higher in the higher pile head connection rigidity models (PR-R and PR-SR), compared to those in the lower pile head connection rigidity models ( $\mathrm{PR}-\mathrm{SH}$ and $\mathrm{PR}-\mathrm{H}$ ).

Figure 20 shows the distributions of bending moments in pile $\mathrm{P} 1$ at horizontal loads of $1.92 \mathrm{kN}$ and $3.84 \mathrm{kN}$, respectively. Comparing the bending moments of the piles in the pile rafts (Cases 4 to 7 ) and those in the pile groups (Cases 2 and 3), the former are smaller than the latter, indicating that the piled raft has the advantage of being able to reduce the possibility of pile failure by bending. The results from the pile groups (Cases 2 and 3 ) indicate that the maximum bending moment is caused at the pile head in PG-R (Case 2), while it is induced at a mid depth of the pile in PG-H (Case 3), although the values of the 


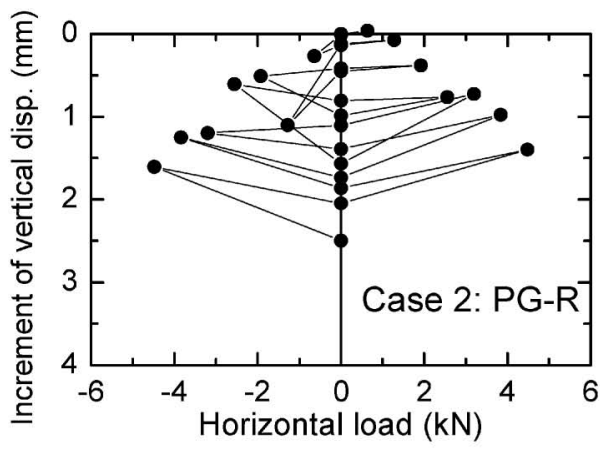

(a) Case 2: PG-R

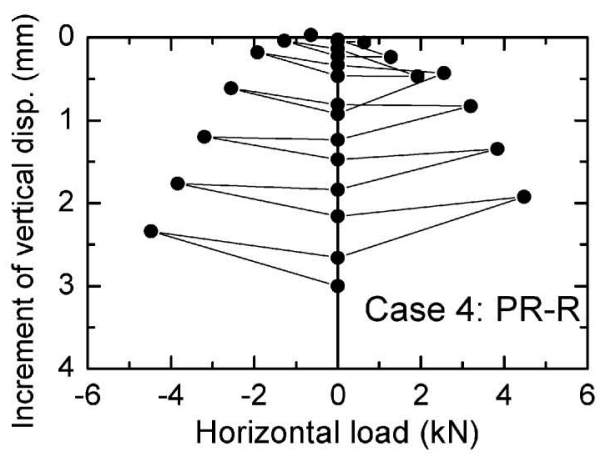

(c) Case 4: PR-R

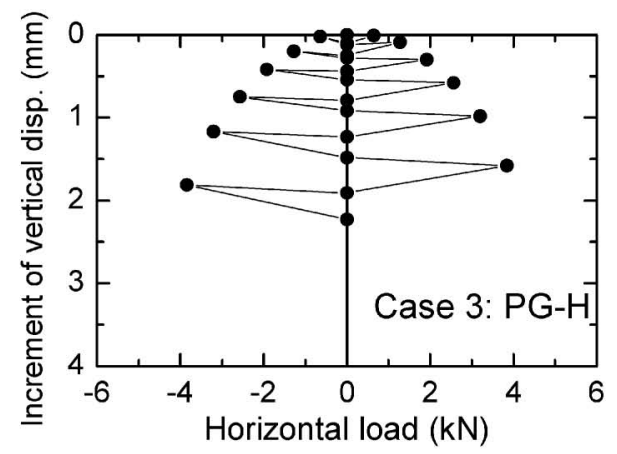

(b) Case 3: PG-H

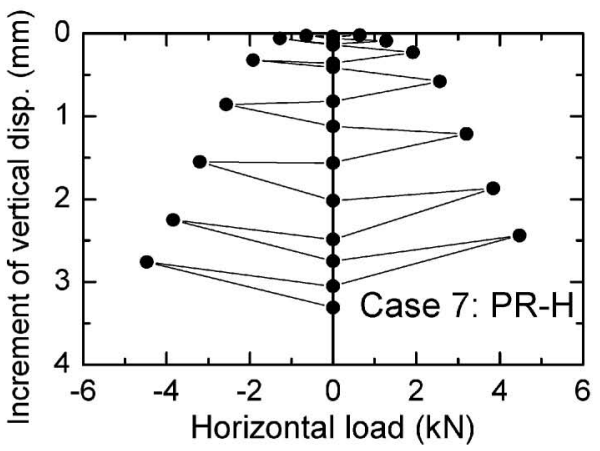

(d) Case 7: PR-H

Fig. 22. Peak horizontal load in each loading cycle versus settlement of the raft

maximum bending moments in both cases are almost equal in these particular test conditions. Similar behaviour of pile bending moments is also found in the case of the piled rafts. These results indicate that the reduction in the pile head connection rigidity does not necessarily reduce the maximum bending moment induced in the piles in either the pile group or in the case of piled rafts.

Figure 21 shows the relationships between the peak horizontal load in each loading cycle and the increment of the axial head force of the piles from the start of horizontal loading. The 'east piles' denote the average of head forces of piles 1 and 2, and the 'west piles' denote that of piles 3 and 4 . In Case 2 (the pile group with the rigid pile head connection) shown in Fig. 21(a), compression forces are induced in the front piles and tension forces are induced in the rear piles, e.g., compression forces are induced in the east piles when the positive horizontal force (force in the direction to the west) is applied. The sum of increment of the pile head force for each pile is 0 , because the rafts in the pile group do not support any vertical load. Similar behaviour was observed in Case 3 (the pile group with the hinged pile head connection) shown in Fig. 21(b). However, the changes in the pile head forces during horizontal loading are much less in Case 3 compared to that in Case 2. In Case 2, the increment of pile head force levelled off at about $1.5 \mathrm{kN}$, suggesting that the pile reached geotechnical failure state. It can be concluded from the results of Figs. 21(a) and (b) that reduction of the pile head connection rigidity suppresses the change in the axial forces in the piles during horizontal loading in case of the pile group, leading to a mitigation of geotechnical and structural pile failures in the vertical direction due to horizontal loading.

In contrast, in the case of the piled rafts (Cases 4 and 7), compression pile head forces were induced in both the front and rear piles due to horizontal loading (see Figs. 21(c) and (d)). This tendency was much clearer in Case 7 (the piled raft with the hinged pile head connection) than in Case 4 (the piled raft with the rigid pile head connection). A possible reason for this is discussed below.

Figure 22 shows the relationship between the horizontal load and the increment of vertical displacement of the raft (settlement is taken as positive) in Case 2: PG-R, Case 3: PG-H, Case 4: PR-R and Case 7: PR-H. The settlement accumulated with increase in loading cycles in all the cases. The settlement was larger in the piled rafts (Cases 4 and 7) than in the pile groups (Cases 2 and 3), contrary to the authors' expectation that the raft in the piled raft plays a role to reduce settlement even in cyclic horizontal loading.

Figure 23 shows the relationship between the horizontal load and the increment of vertical displacement of the raft alone (Case 1). See Fig. 12 for the corresponding horizontal load versus horizontal displacement. The raft alone foundation (Case 1) settled more than the other foundations. It can be inferred from the comparison of Figs. 22 and 23 that the compression of the soil beneath the raft occurred during horizontal loading due to the negative dilatancy of the soil caused by the shear stresses induced by the shear resistance at the raft base. It may be 


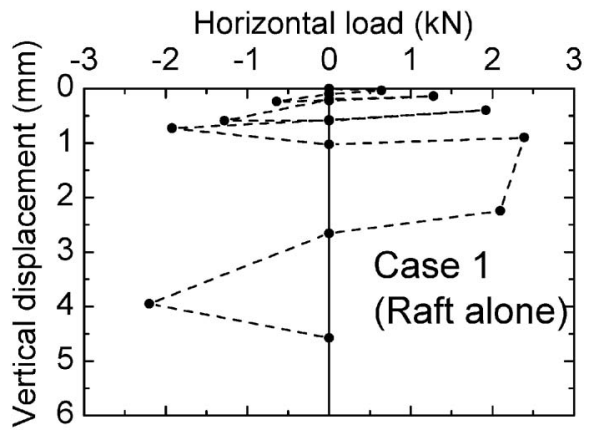

Fig. 23. Relationship between horizontal load and vertical displacement of the raft alone

reasonable to think that the negative dilatancy effect was larger in the soils near the raft base, and the base resistance of the pile was relatively large as was shown in Fig. 9. In such a situation, the negative dilatancy of the soils beneath the raft may lead to the reduction of the vertical pressure at the raft base, which in turn is compensated for by the increase in the axial forces of the piles.

The test results shown in Fig. 21 suggests that piled raft with 'end-bearing' piles should be avoided if the soils near the ground surface are prone to compress when subjected to cyclic horizontal loading such as earthquakes.

\section{ANALYSES OF LOADING TESTS}

The load tests mentioned above were analysed using a simplified analysis method in order to discuss the test results in more detail, and in order to examine the applicability of the simplified method as a design tool.

\section{Analytical Method}

The analyses of the static vertical and horizontal load test results of the model foundations were carried out using a computer program PRAB developed by Kitiyodom and Matsumoto $(2002,2003)$ which has been developed to estimate the deformation and load distribution of piled raft foundations subjected to vertical, horizontal, and moment loads. In this program, a hybrid model is employed in which the flexible raft is modelled as thin plates, the piles as elastic beams, and the soil is treated as interactive springs as shown in Fig. 24. Both the vertical and horizontal resistances of the piles as well as that of the raft base are incorporated into the model. The interactions between structural members, such as pile-soil-pile, pile-soil-raft and raft-soil-raft interactions, are taken into account based on Mindlin's solutions (Mindlin, 1936) for both vertical and horizontal forces. The considered soil profile may be homogeneous semi-infinite, arbitrarily layered and/or underlain by a rigid bed stratum. The non-linear deformation of the foundations is calculated by employing the bi-linear (elastic-perfectly plastic) response of soil springs.

For soil profiles that are arbitrarily layered and/or underlain by a rigid bed stratum, the vertical soil spring, $K_{\mathrm{z}}^{\mathrm{R}}$, at raft nodes, the vertical soil spring, $K_{\mathrm{z}}^{\mathrm{Pb}}$, at pile base

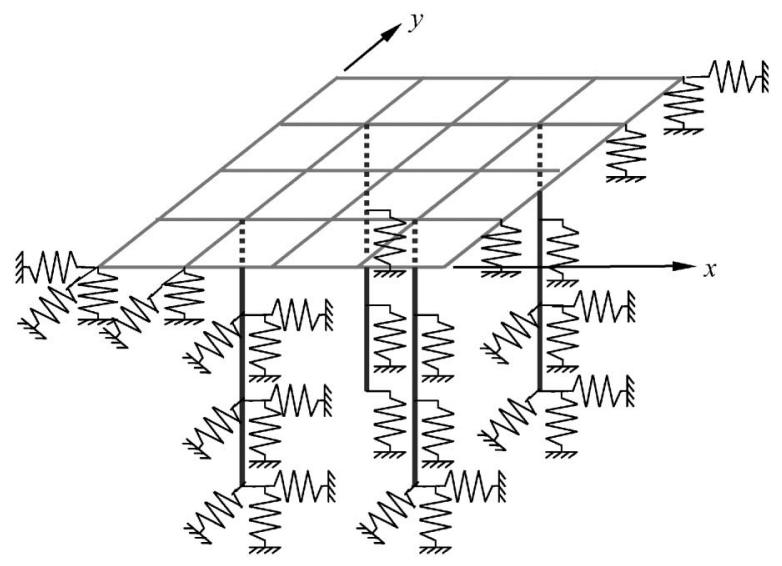

Fig. 24. Plate-beam-spring modelling of a piled raft

nodes and the general expression $r_{\mathrm{m}}$ for the vertical soil spring, $K_{\mathrm{z}}^{\mathrm{P}}$, at pile shaft nodes are estimated to include the influence of finite layered soils following Lee (1991).

$$
\begin{aligned}
& K_{\mathrm{z}}^{\mathrm{R}}=\frac{4 \bar{G} a}{1-v_{\mathrm{s}}} \times \frac{1}{\{1-\exp (-h / 2 a)\}} \\
& K_{\mathrm{z}}^{\mathrm{Pb}}=\frac{4 G_{\mathrm{b}} r_{\mathrm{o}}}{1-v_{\mathrm{s}}} \times \frac{1}{\left\{1-\exp \left(-h^{*} / 2 r_{\mathrm{o}}\right)\right\}} \\
& K_{\mathrm{z}}^{\mathrm{P}}=\frac{2 \pi G \Delta L}{\ln \left(r_{\mathrm{m}} / r_{\mathrm{o}}\right)} \\
& r_{\mathrm{m}}=2.5\left[\frac{\sum_{i=1}^{n_{p}} G_{\mathrm{i}} L_{\mathrm{i}}}{\mathrm{G}_{\mathrm{m}} L} \sqrt{\frac{G_{\mathrm{m}}}{G_{\mathrm{b}}}} \chi L\left(1-v_{\mathrm{s}}\right)\right], \\
& \chi=1-\exp (1-h / L)
\end{aligned}
$$

where $h$ is the finite soil depth, $h^{*}$ is the distance between the pile base and the rigid bed stratum, $a$ is the equivalent radius of the raft element, $r_{\mathrm{o}}$ is the pile radius, $v_{\mathrm{s}}$ is the Poisson's ratio of the soil, $\Delta L$ and $L$ are the pile segment length and the pile length. $G_{\mathrm{m}}$ is the maximum soil shear modulus, $G_{\mathrm{b}}$ is the soil shear modulus below pile base, $G_{\mathrm{i}}$ and $L_{\mathrm{i}}$ are the shear modulus at and the length of pile embedded in soil layer $i$, and $n_{\mathrm{p}}$ is the total number of soil layers along the pile length. $\bar{G}$ is the equivalent shear modulus which can be determined following Fraser and Wardle (1976):

$$
\begin{aligned}
\bar{G} & =\frac{\bar{E}_{\mathrm{s}}}{2\left(1+v_{\mathrm{s}}\right)} \\
\frac{1}{\bar{E}_{\mathrm{s}}} & =\sum_{i=1}^{n} \frac{1}{E_{\mathrm{si}}} \Delta I_{i} / \Delta I_{\text {total }}
\end{aligned}
$$

where $\bar{E}_{\mathrm{s}}$ is the equivalent Young's modulus, $E_{\mathrm{si}}$ is the Young's modulus for soil layer $i$ in the $n$-layered system, and $I$ is the vertical settlement influence factor which is given by Harr (1966). $\Delta I_{i}=I\left(z_{\text {top }}^{i}\right)-I\left(z_{\text {bottom }}^{i}\right)$ where $z_{\text {top }}^{i}$ and $z_{\text {bottom }}^{i}$ are the depths below the surface of the top and bottom of layer $i$ and $\Delta I_{\text {total }}=I(0)-I(h)$ where $h$ is the depth of the base of the bottom layer.

The horizontal springs, $K_{x}^{\mathrm{R}}$ and $K_{y}^{\mathrm{R}}$, at raft nodes, and 
horizontal springs, $K_{x}^{\mathrm{Pb}}$ and $K_{y}^{\mathrm{Pb}}$, at pile base nodes are estimated by means of Eqs. (8) and (9), and the horizontal soil spring, $K_{x}^{\mathrm{P}}$ and $K_{y}^{\mathrm{P}}$, at pile shaft nodes are estimated by means of Eq. (10). As for loading in the horizontal direction, the near surface soil layers tend to be the most influential. Therefore, the soil shear modulus $G_{\mathrm{r}}$, which is the shear modulus of the soil layer just beneath the raft, is employed in the estimation of the horizontal springs at the raft nodes.

$$
\begin{aligned}
& K_{x}^{\mathrm{R}}=K_{y}^{\mathrm{R}}=\frac{32\left(1-v_{\mathrm{s}}\right) G_{\mathrm{r}} a}{7-8 v_{\mathrm{s}}} \\
& K_{x}^{\mathrm{Pb}}=K_{y}^{\mathrm{Pb}}=\frac{32\left(1-v_{\mathrm{s}}\right) G_{\mathrm{b}} r_{0}}{7-8 v_{\mathrm{s}}} \\
& K_{x}^{\mathrm{P}}=K_{y}^{\mathrm{P}}=\zeta E_{\mathrm{s}} \Delta L
\end{aligned}
$$

where $\zeta=p D / \rho E_{\mathrm{s}}$ in which $p$ is the horizontal distributed force acting along the pile element, $D$ is the pile diameter and $\rho$ is the corresponding horizontal displacement at each pile node calculated using the integral equation method by Poulos and Davis (1980).

When using PRAB to analyse the problem of pile group, the soil resistance (soil spring value) at the raft base is set as 0 .

\section{Analytical Conditions}

It has been described in Fig. 4 and Eq. (1) that the shear modulus, $G$, of the sand is dependent on the effective confining pressure, $p_{0}$. In the analyses, the value of $G_{\text {ref }}$ was set at $17000 \mathrm{kPa}$ throughout. In the analyses, the model ground of $1 \mathrm{~m}$ in thickness was divided into 15 soil layers.

The effective confining pressure, $p_{0}$, at any depth was calculated by

$$
p_{0}=\left(1+2 K_{0}\right) \sigma_{\mathrm{v}}^{\prime} / 3
$$

where $\sigma_{v}^{\prime}$ is the overburden pressure of the soil, and the coefficient of earth pressure at rest, $K_{0}$, was estimated by Jâky's empirical formula.

$$
K_{0}=1-\sin \phi^{\prime}
$$

where $\phi^{\prime}$ is the soil internal friction angle and was obtained from the triaxial test results (see Fig. 5). Note that it was essential to carry out the triaxial tests at very low stress level such as 5,10 or $20 \mathrm{kPa}$, since the stresses at pile base level was $9.13 \mathrm{kPa}$. However, it was very difficult to conduct such triaxial tests with the triaxial test equipment available to us.

The horizontal resistance at the raft base, $q_{\mathrm{h}}$, was calculated by Eq. (13):

$$
q_{\mathrm{h}}=c+\mu_{\mathrm{b}} \sigma_{\mathrm{vb}}^{\prime}
$$

where $c$ is the cohesion between the raft base and the soil, $\mu_{\mathrm{b}}$ is the friction coefficient at the raft base, and $\sigma_{\mathrm{vb}}^{\prime}$ is the vertical stress at the raft base.

The cohesion and the coefficient of friction between the raft base and the soil were set at 0 and $0.84\left(=\tan \phi^{\prime}\right)$, respectively, from the results of triaxial tests of Toyoura sand, because Toyoura sand was glued to the raft base.

The ultimate vertical pressure at the raft base, $q_{\mathrm{u}}$, was calculated by Eq. (14) following the specifications of Architectural Institute of Japan (2001).

$$
q_{\mathrm{u}}=\alpha \cdot c \cdot N_{\mathrm{c}}+\beta \cdot \gamma_{1} \cdot B \cdot \eta \cdot N_{\gamma}+\gamma_{2} \cdot D_{\mathrm{f}} \cdot N_{\mathrm{q}}
$$

where $\alpha=1.2, \beta=0.3$ for a square raft with a width of $B$, $N_{\mathrm{c}}=75.3, N_{\gamma}=93.7$ for $\phi^{\prime}=40$ degrees, $\eta=\left(B / B_{0}\right)^{-1 / 3}$, and $B_{0}=1.0 \mathrm{~m}$.

The maximum shaft resistance, $f_{\max }$, and limit horizontal pressure, $p_{\max }$, of the piles were estimated by Eqs. (15) and (16), respectively.

$$
\begin{aligned}
& f_{\text {max }}=\mu \cdot \gamma \cdot z \cdot K_{0} \\
& p_{\text {max }}=\alpha_{\mathrm{p}} \cdot \gamma \cdot z \cdot K_{\mathrm{p}}
\end{aligned}
$$

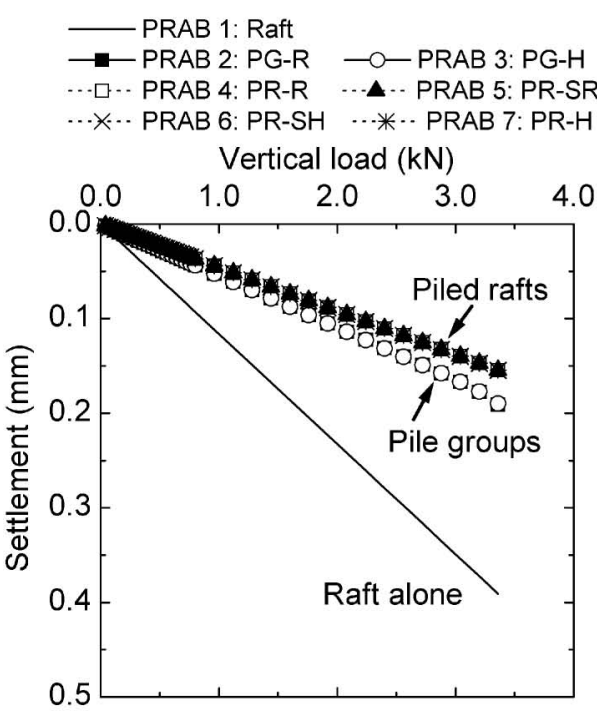

(a) Analyses results

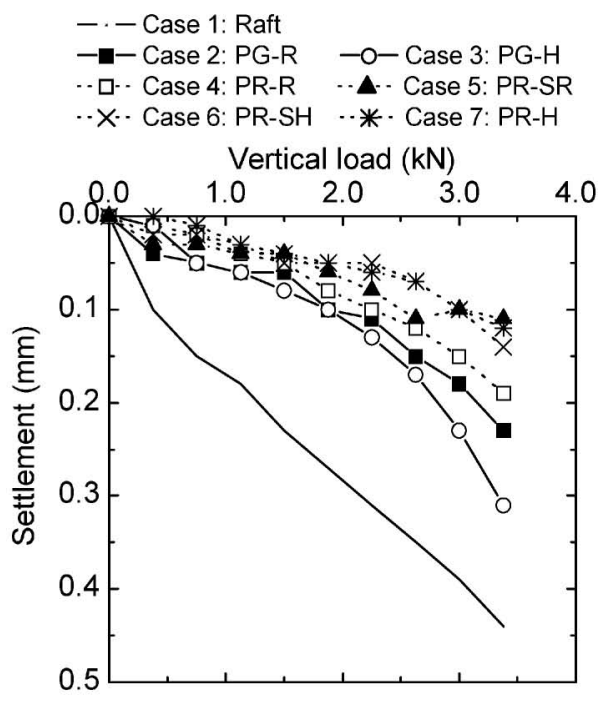

(b) Experimental results

Fig. 25. Comparison of calculated and measured load-settlement relationships 
where $\gamma$ is the unit weight of the soil, $z$ is the depth from the ground surface, $\mu$ is the coefficient of friction of the pile shaft, $K_{\mathrm{p}}$ is the Rankine passive pressure coefficient, and $\alpha_{\mathrm{p}}$ is an empirical coefficient.

The value of $\mu$ was set at 0.84 because Toyoura sand was glued to the pile shaft. The value of $\alpha_{\mathrm{p}}$ was assumed as 3.0 following the proposal of Broms (1964), and $K_{\mathrm{p}}$ is given by Eq. (17).

$$
K_{\mathrm{p}}=\left(1+\sin \phi^{\prime}\right) /\left(1-\sin \phi^{\prime}\right)
$$

In the estimation of the shear modulus of sand and the maximum shaft resistance of the piles located just beneath the raft, the effect of the increase in the vertical stress of the soil due to the vertical load transferred

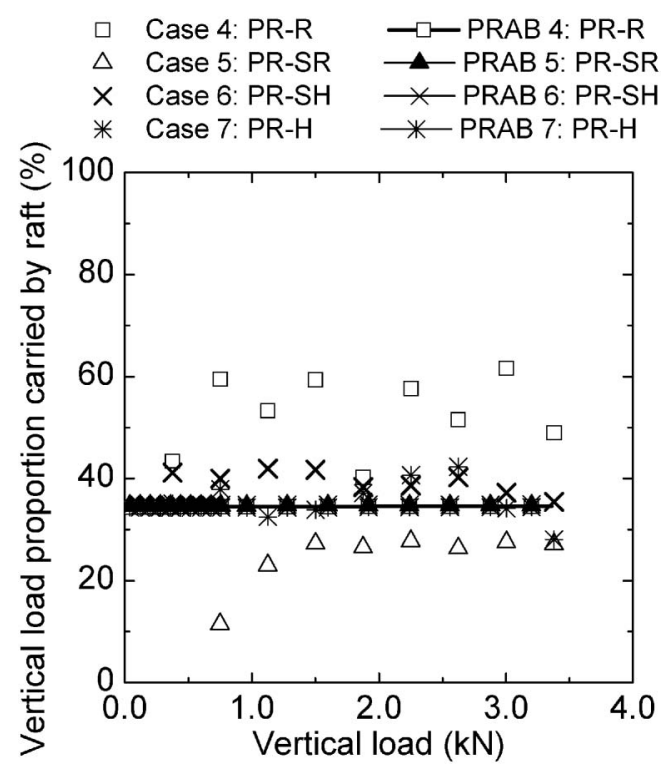

Fig. 26. Comparison of calculated and measured proportions of vertical load carried by raft

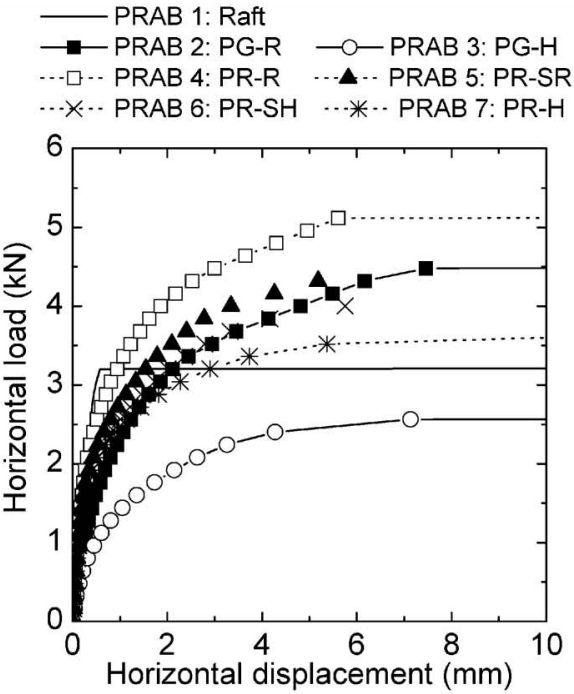

(a) Analyses results through the raft base should be taken into account. In the analyses, it was assumed that the soil just beneath the raft to a depth of $300 \mathrm{~mm}$ have a vertical stress equal to the vertical pressure at the raft base.

The maximum pile base resistance, $R_{\mathrm{p}}$, was estimated by Eq. (18).

$$
R_{\mathrm{p}}=q_{\mathrm{c}} \cdot A_{\mathrm{p}}
$$

where $A_{\mathrm{p}}$ is the pile base area and $q_{\mathrm{c}}=5000 \mathrm{kPa}$ from the CPT results.

Note that although cyclic horizontal loading was applied to the model foundations, analyses of monotonic horizontal loading of the model foundations were carried out.

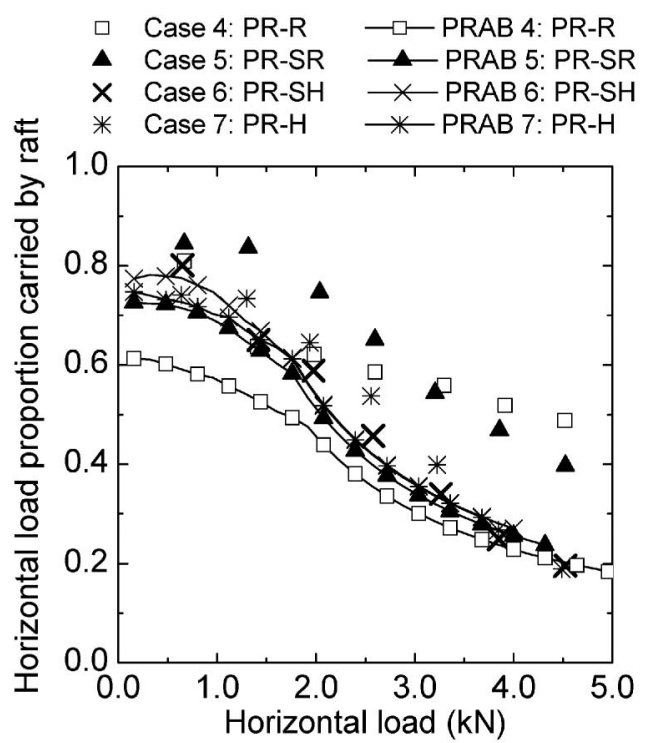

Fig. 28. Comparison of calculated and measured proportions of horizontal load carried by raft
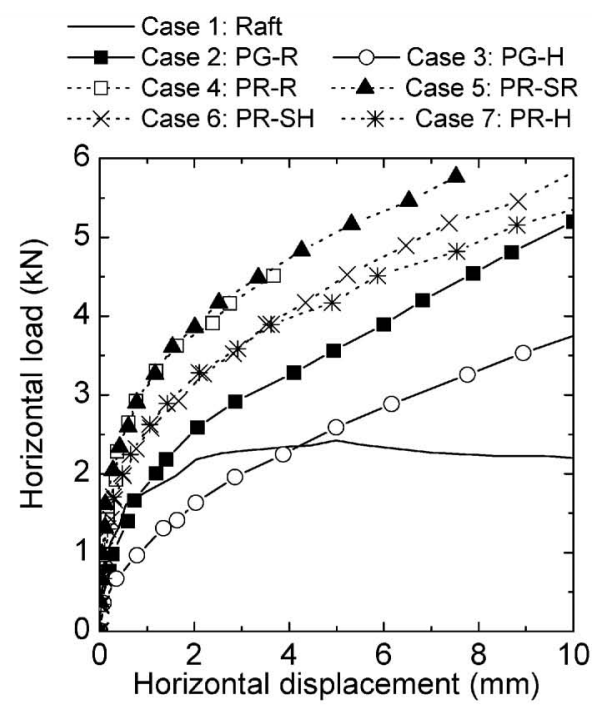

(b) Experimental results

Fig. 27. Comparison of calculated and measured horizontal load-horizontal displacement relationships 


\section{Analytical Results}

Figures 25(a) and (b) show the load-settlement behaviour of the model foundations calculated using PRAB and those obtained from the model load tests, respectively. The measured behaviours were indicated again for a purpose of comparison. Although there are some differences in shape of the load-settlement curves obtained from the model load tests and those calculated using PRAB, there is good agreement in the trend between the measured values and the calculated values for all cases. At the same vertical load, pile groups settle more than piled rafts. The load-settlement curves are almost identical for the same type of foundation regardless of pile head connection rigidities, i.e., the influence of the rigidity of the pile head connection on the behaviour of the foundation in the vertical loading is little.

Figure 26 shows the proportions of the vertical load carried by the raft in the cases of piled rafts. It is seen from the calculated results that the proportions of the vertical load carried by the raft are about 0.35 for all types of pile head connection condition. This leads to a conclusion that the rigidity of the pile head connection has little influence on the behaviour of the foundations subjected to vertical load.

Figures 27(a) and (b) show the horizontal loaddisplacement behaviour of the model foundations calculated using PRAB and those obtained from the horizontal load tests, respectively. It can be seen from both experimental and analytical results that the initial horizontal stiffness is higher in the case of piled raft than that of corresponding pile group. For the same type of foundation, the higher horizontal stiffness and horizontal resistance can be found in the foundation that has higher rigidity of pile head connection. In the experiments, the

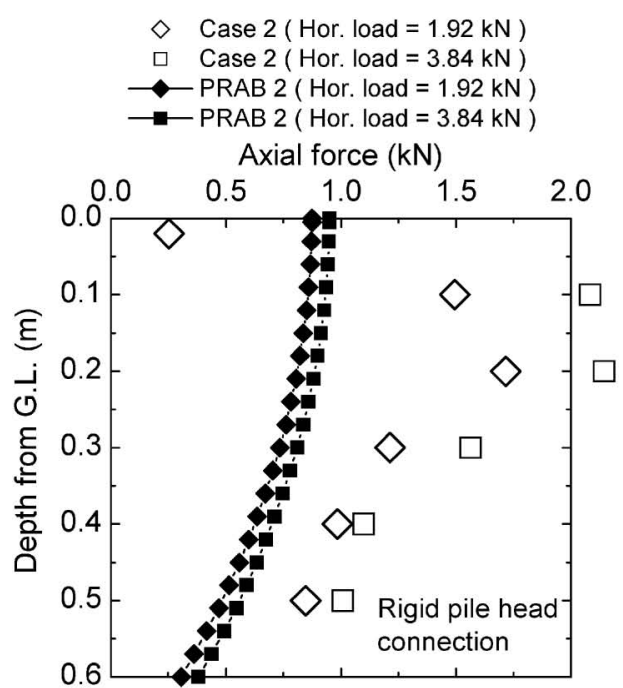

(a) Case 2: PG-R

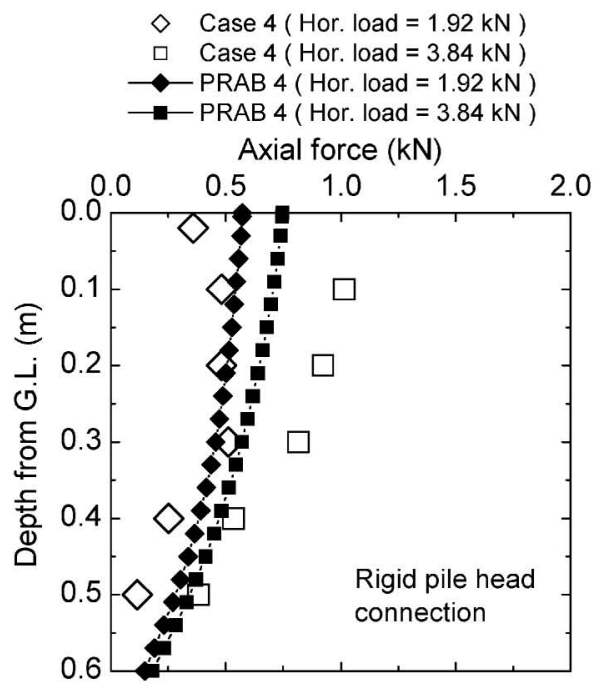

(c) Case 4: PR-R

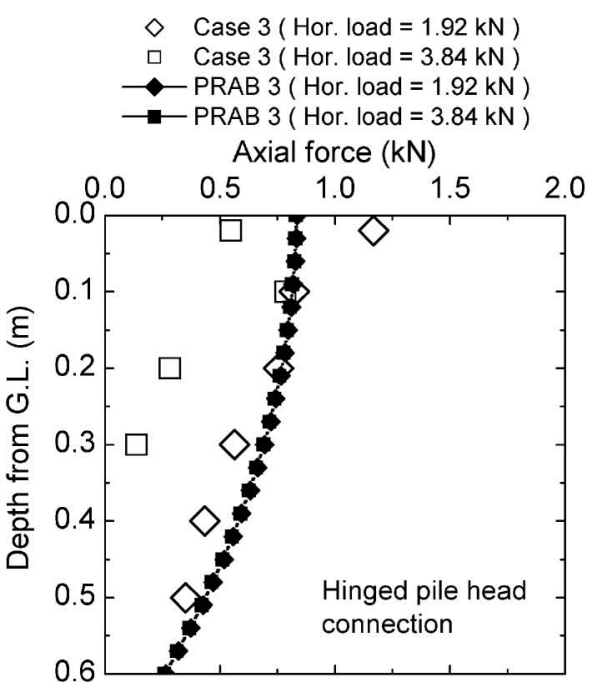

(b) Case 3: PG-H

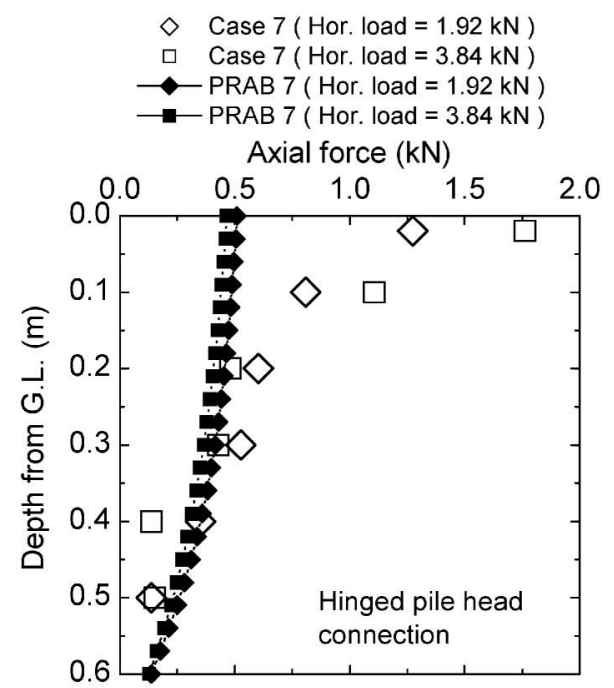

(d) Case 7: PR-H

Fig. 29. Comparison of calculated and measured distributions of axial forces in pile 


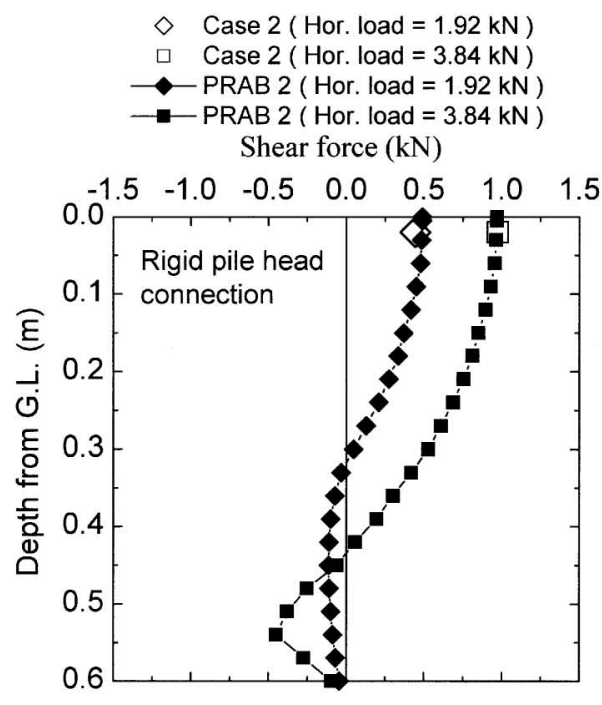

(a) Case 2: PG-R

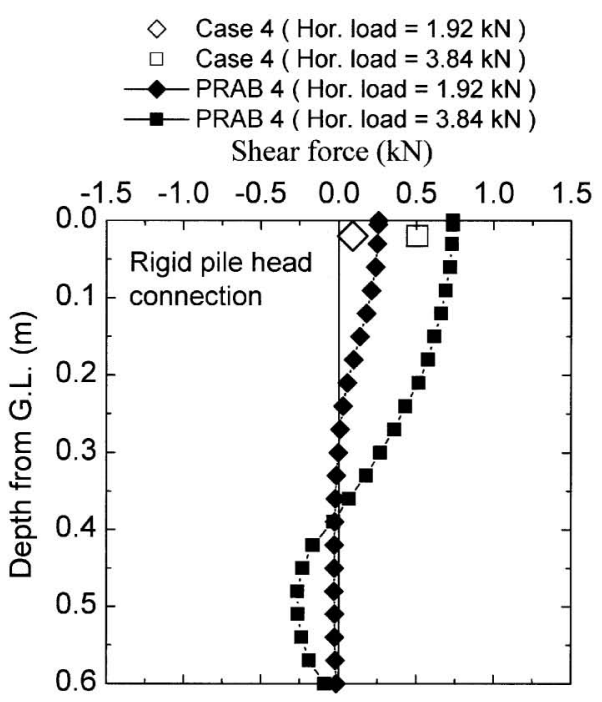

(c) Case 4: PR-R

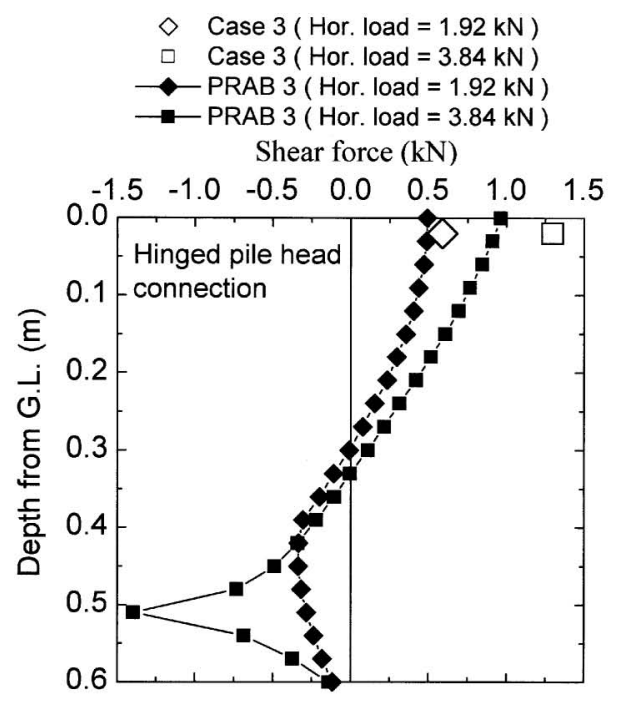

(b) Case 3: PG-H

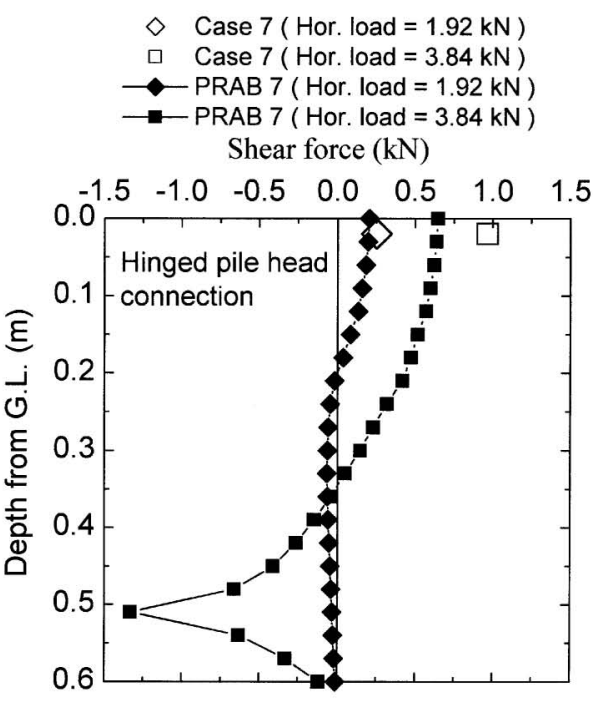

(d) Case 7: PR-H

Fig. 30. Comparison of calculated and measured distributions of shear forces in pile

horizontal load continued to increase even after the horizontal displacement exceeds $10 \mathrm{~mm}$ in all the cases, while the calculated results do not simulate this experimental result well. The calculation results match with the experimental results until a horizontal displacement of $4 \mathrm{~mm}$ that corresponds to $10 \%$ of the pile diameter.

Figure 28 shows the proportions of the horizontal load carried by the raft in the cases of piled raft calculated using PRAB and those obtained from the horizontal load tests. There is reasonable agreement in the trend between the calculated results and the experimental results. It is seen from the analysis results that the piles in the piled raft with the rigid pile head connection carry more of the horizontal load than the piled rafts with less rigid pile head connections in the initial loading stages. After the horizontal load reaches $2.5 \mathrm{kN}$, the proportion of horizontal load carried by the raft for all cases is almost

\section{identical.}

Figure 29 shows the calculated and measured distributions of axial forces in pile $\mathrm{P} 1$ (front pile in the analysis) at horizontal loads of $1.92 \mathrm{kN}$ and $3.84 \mathrm{kN}$ for Case 2: PG-R, Case 3: PG-H, Case 4: PR-R and Case 7: PR-H, respectively. The analyses did not simulate the experimental results well. As mentioned earlier, analyses of monotonic horizontal loading of the model foundations were carried out, although cyclic horizontal loading was applied to the model foundations. Settlements of the foundations occurred during cyclic horizontal loading, as have been shown in Fig. 22. It is inferred that the axial forces of the piles were influenced by the settlements of the foundations during cyclic horizontal loading. Since the simplified analysis method is not capable of simulating such complicated behaviour, there was poor accordance between the calculated and measured axial forces 


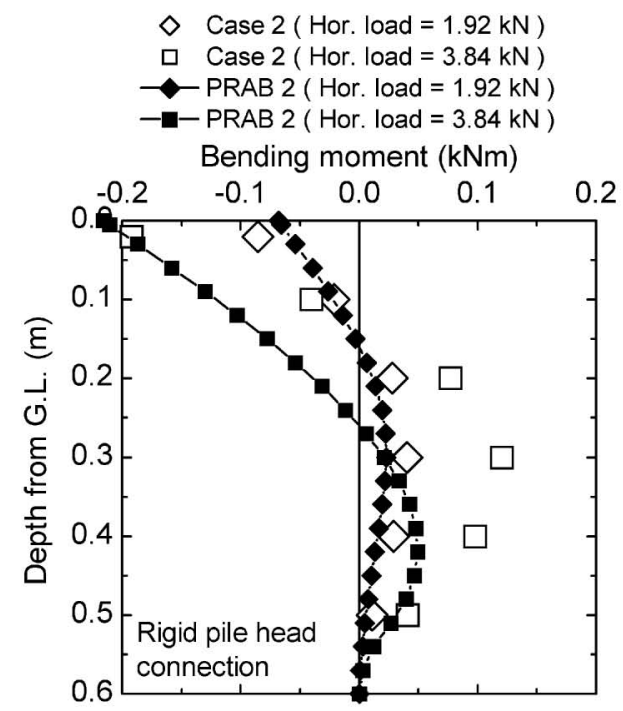

(a) Case 2: PG-R

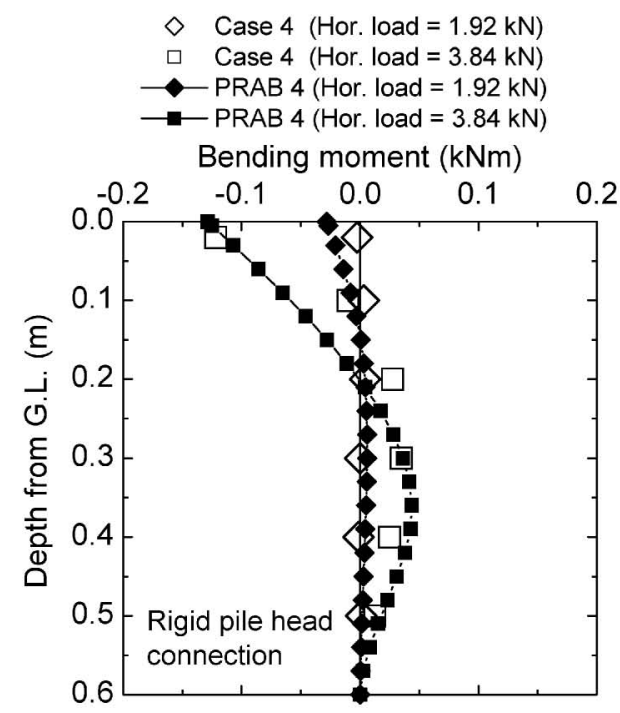

(c) Case 4: PR-R

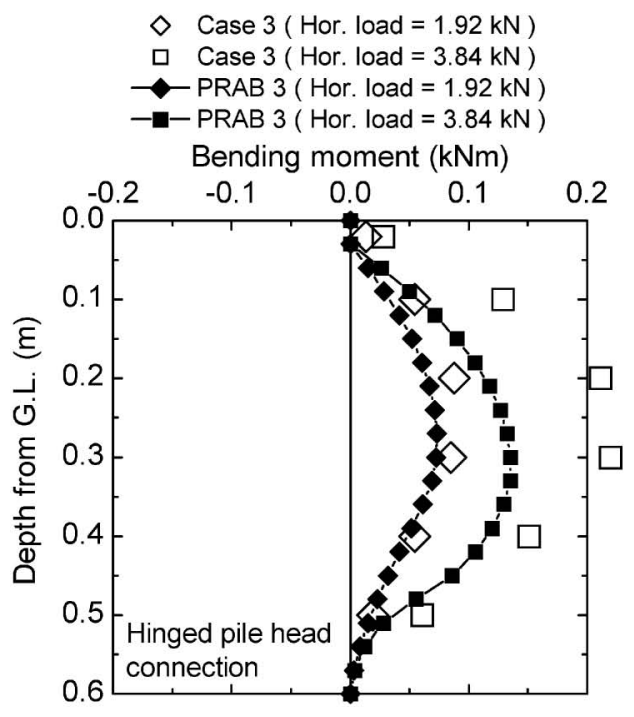

(b) Case 3: PG-H

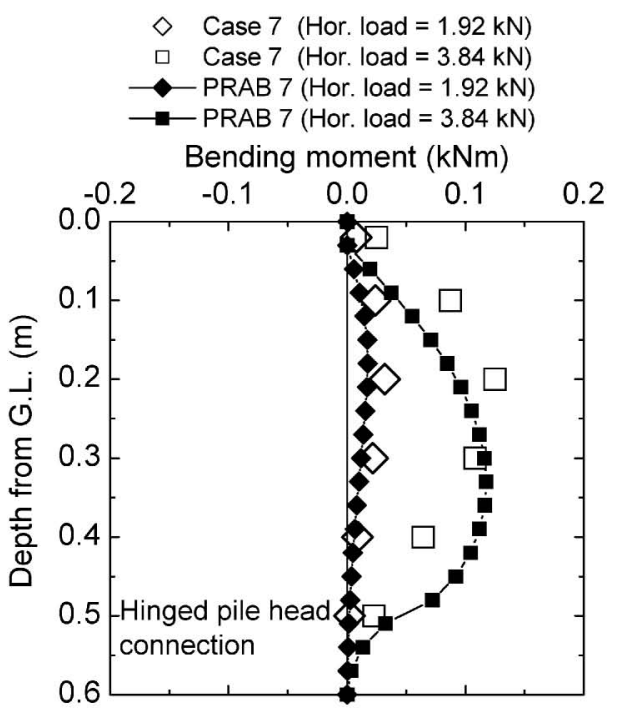

(d) Case 7: PR-H

Fig. 31. Comparison of calculated and measured distributions of bending moments in pile

in the pile.

Figure 30 shows the calculated and measured distributions of shear forces in pile $\mathrm{P} 1$ (front pile in the analysis) at horizontal loads of $1.92 \mathrm{kN}$ and $3.84 \mathrm{kN}$ for Case 2: PG-R, Case 3: PG-H, Case 4: PR-R and Case 7: PR-H, respectively. Shear force was measured only near the pile head. The calculated shear forces at the pile head were in good agreement with the measured values, although the calculation underestimated the measured values at a horizontal load of $3.84 \mathrm{kN}$ in Case $3: \mathrm{PG}-\mathrm{H}$ and Case 7 : PR-H.

Figure 31 shows the calculated and measured profiles of the bending moments in the piles at horizontal loads of $1.92 \mathrm{kN}$ and $3.84 \mathrm{kN}$ for Case 2: PG-R, Case 3: PG-H, Case 4: PR-R and Case 7: PR-H, respectively. It is seen that although the analysis results underestimate the bending moments of the piles in the pile groups (Cases 2 and
3), the analysis results simulate the measured results in terms of the trend observed. It can be seen that the analysis results match the measured values for the piled rafts (Cases 4 and 7) well.

\section{CONCLUSIONS}

A series of experimental and analytical studies on the behaviour of model piled rafts and model pile groups using dry sand subjected to a static vertical load and a static horizontal load have been carried out in order to investigate the influence of various pile head connection conditions on the behaviours of model piled rafts as well as model pile groups. In the load tests, the behaviours of the model foundations during horizontal loading, with a particular focus on horizontal stiffness and the rotation of the foundation, the load proportions between the raft 
and the piles, and the bending moments and shear forces generated in the piles were investigated in detail.

The main findings from the load tests are as follows:

From the vertical loading stage,

1. The vertical settlement stiffness of the piled raft is larger than that of the pile group and the raft alone for smaller loads, and decreases to that of the raft alone as the vertical load increases.

2. The pile head connection condition has little influence on the behaviours of the pile groups and the piled rafts subjected to vertical load alone.

3. Mobilised shaft resistance along the upper part of the pile in piled rafts is much smaller than that in the pile group due to interaction between the raft and the piles through the ground.

The following points can be made with regard to the cyclic horizontal loading stage:

4. The horizontal stiffness of the piled rafts is larger than that of a pile group with the same configuration as the piled raft, because the raft acts effectively as a 'horizontal displacement reducer'.

5. The bending moments of the piles in the piled raft are reduced, compared with those in the pile group.

6. In the case of the piled rafts, rotation of the raft decreases as the pile head connection rigidity becomes lower, although the horizontal stiffness also becomes lower.

7. The horizontal loads carried by the piles in the piled rafts are not influenced by the pile head connection rigidity, whereas the horizontal load proportion carried by the raft becomes lower as the pile head connection becomes less rigid.

The latter part of the paper includes a description of the analyses of the experiments carried out using a simplified three-dimensional deformation analysis method with soil properties estimated using well-known theoretical or empirical equations in order to examine the simplified analytical method for design. In the analyses of horizontal load tests of the model foundations, a monotonic horizontal loading was analysed, although cyclic horizontal loading was carried out in the experiments. The analyses simulated the behaviours of the model foundations under vertical loading well. As for horizontal loading, the calculated results were tolerable, except for axial forces in piles, for preliminary design. It was suggested that more sophisticated analysis methods are required to design piled raft foundations subjected to cyclic horizontal loading.

\section{ACKNOWLEDGEMENTS}

The authors deeply thank the members of Research Group on Piled Raft Foundation (2002 to 2007), Masateru Fujita (ANDO Corporation), Yoshio Takeuchi (Nishimatsu Construction), Hironori Horii (Hazama Corporation), Hideaki Hasei (Sumitomo Mitsui Construction) for their support in conducting experiments, and valuable discussions and suggestions in summarising the paper.

\section{REFERENCES}

1) Architectural Institute of Japan (2001): Recommendations for Design of Building Foundation (in Japanese).

2) Broms, B. B. (1964): Lateral resistance of piles in cohesionless soils, Journal of Soil Mechanics and Foundations Division, ASCE, 90(SM3), 123-156.

3) Fraser, R. A. and Wardle, L. J. (1976): Numerical analysis of rectangular rafts on layered foundations, Géotechnique, 26(4), 613-630.

4) Harr, M. E. (1966): Foundations of Theoretical Soil Mechanics, McGraw-Hill: New York.

5) Horikoshi, K., Matsumoto, T., Hashizume, Y., Watanabe, T. and Fukuyama, H. (2003a): Performance of piled raft foundations subjected to static horizontal loads, International Journal of Physical Modelling in Geotechnics, 3(2), 37-50.

6) Horikoshi, K., Matsumoto, T., Hashizume, Y. and Watanabe, T. (2003b): Performance of piled raft foundations subjected to dynamic loading, International Journal of Physical Modelling in Geotechnics, 3(2), 51-62.

7) Kakurai, M. (2003): Study on vertical load transfer of piles, Dr. Thesis, Tokyo Institute of Technology, 304p (in Japanese).

8) Kitiyodom, P. and Matsumoto, T. (2002): A simplified analysis method for piled raft and pile group foundations with batter piles, International Journal for Numerical and Analytical Methods in Geomechanics, 26, 1349-1369.

9) Kitiyodom, P. and Matsumoto, T. (2003): A simplified analysis method for piled raft foundations in non-homogeneous soils, International Journal for Numerical and Analytical Methods in Geomechanics, 27, 85-109.

10) Lee, C. Y. (1991): Discrete layer analysis of axially loaded piles and pile groups, Computers and Geotechnics, 11, 295-313.

11) Matsumoto, T., Fukumura, K., Kitiyodom, P., Horikoshi, K. and Oki, A. (2004a): Experimental and analytical study on behaviour of model piled rafts in sand subjected to horizontal and moment loading, International Journal of Physical Modelling in Geotechnics, 4(3), 1-19.

12) Matsumoto, T., Fukumura, K., Horikoshi, K. and Oki, A. (2004b): Shaking table tests on model piled rafts in sand considering influence of superstructures, International Journal of Physical Modelling in Geotechnics, 4(3), 21-38.

13) Mindlin, R. D. (1936): Force at a point interior of a semi-infinite solid, Physics, 7, 195-202.

14) Poulos, H. G. and Davis, E. H. (1980): Pile Foundation Analysis and Design, John Wiley and Sons, New York. 